ERDA/JPL/954144-76/02

\title{
SILICON RIBBON GROWTH BY A CAPILLARY ACTION SHAPING TECHNIQUE
}

Annual Report

G. H. Schwuttke

T. F. Ciszek

A. Kran

June 15, 1976

Work Performed Under Contract No. JPL-954144

East Fishkill Laboratory

International Business Machines Corporation

Hopewell Junction, New York

\section{ENERGY RESEARCH AND DEVELOPMENT ADMINISTRATION}

\section{Division of Solar Energy}




\section{DISCLAIMER}

This report was prepared as an account of work sponsored by an agency of the United States Government. Neither the United States Government nor any agency Thereof, nor any of their employees, makes any warranty, express or implied, or assumes any legal liability or responsibility for the accuracy, completeness, or usefulness of any information, apparatus, product, or process disclosed, or represents that its use would not infringe privately owned rights. Reference herein to any specific commercial product, process, or service by trade name, trademark, manufacturer, or otherwise does not necessarily constitute or imply its endorsement, recommendation, or favoring by the United States Government or any agency thereof. The views and opinions of authors expressed herein do not necessarily state or reflect those of the United States Government or any agency thereof. 


\section{DISCLAIMER}

Portions of this document may be illegible in electronic image products. Images are produced from the best available original document. 


\title{
NOTICE
}

This report was prepared as an account of work sponsored by the United States Government. Neither the United States nor the United States Energy Research and Development Administration, nor any of their employees, nor any of their contractors, subcontractors, or their employees, makes any warranty, express or implied, or assumes any legal liability or responsibility for the accuracy, completeness or usefulness of any information, apparatus, product or process disclosed, or represents that its use would not infringe privately owned rights.

This report has been reproduced directly from the best available copy.

Available from the National Technical Information Service, U. S. Department of Commerce, Springfield, Virginia 22161

\author{
Price: Paper Copy $\$ 4.50$ (domestic) \\ $\$ 7.00$ (foreign) \\ Microfiche $\$ 2.25$ (domestic) \\ $\$ 3.75$ (foreign)
}




\section{SILICON RIBBON GROWTH BY A CAPILLARY ACTTON SHAPTNG TECINIQZUE}

G. H. Schwuttke, Principal Investigator, 914-897-3,140

Internationa1 Business Machines Corporation System Products Division, East Fishkill Laboratories Hopewell Junction, New York 12533

Annual Report

(Quarterly Technical Progress Report Number 4) June 15, 1976

prepared by

G. H. Schwuttke, T. F. Ciszek, and A. Kran

Under JPL Contract Number: 954144

(Subcontract under NASA Contract NAS7-100)

(Task Order No. RD-152)

Effective Date of Contract: 5/8/75

Contract Expiration Date: 12/31/16

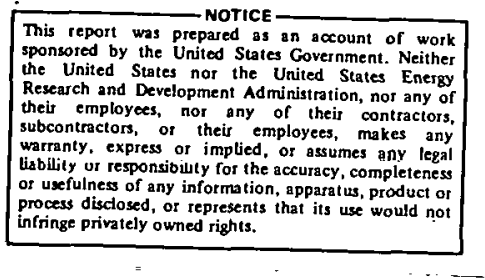

cont of work theis employees, nor any of their contractors, warranty, expess or inplied, or ass, maks any legal az usefulnes of any inform tion, aproy, completeness process disclosed, or represents that its use would no

This work was performed for the Jet Propulsion Laboratory, California Institute of Technology, under NASA Contract NAS7-100 for the U.S. Energy Research and Development Administration, Division of Solar Energy.

The JPL Low-Cost Silicon Solar Array Project is funded by ERDA and forms part of the ERDA Photovoltaic Conversion Program to initiate a major effort toward the development of low-cost solar arrays. 
CONTENTS

$\underline{\text { Page }}$

TECHNICAL CONTENT STATEMENT .............. iii

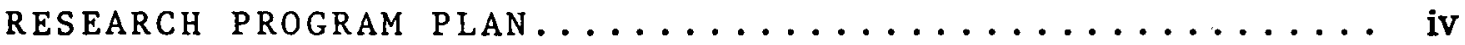

FOURTH QUARTER HIGHLIGHTS ................. v

CRYSTAL GROWTH....................... 1

1. Introduction........................ 1

2. Capillary Action Shaping Technique Die Design

Considerations....................... 4

3. Growth of $38-m m-w i d e$ Ribbons.............. 11

4. References......................... 13

5. Acknowledgment..................... 13

Appendix 1. DIMENSIONAL CHARACTERISTICS OF SOME

RIBBONS GROWN DURING AUGUST 1975 -

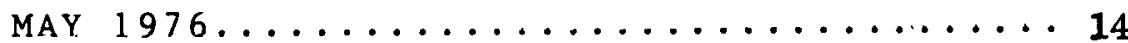

ANALYSIS OF VAPOR-DEPOSITED SILICON CARBIDE FILMS

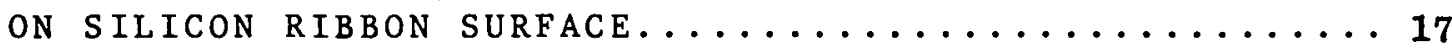

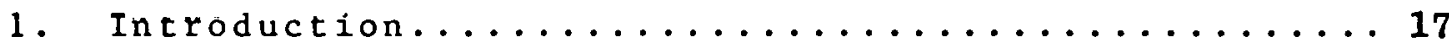

2. Analysis of Surface Films on Ribbons.......... 18

3. Optical Microscopy of Surface Films............ 19

4. Transmission Electron Microscopy of Surface Films.. 19

5. Summary ......................... 32

6. References......................... 33

CURKENT OUTLOOK FOR LARGE-AREA SILICON SHEET--A

TECHNOLOGY PROJECTION................. 
1. Introduction........................ 34

2. Technology Forecasting Methodology............. 35

2.1 Genera1........................... 35

2.2 Forecasting Technique.................. 37

2.3 Baseline Definition.................. 39

2.4 Parameter Projection and Numerical Evaluation..... 42

3. Computer Program for Technology Forecasting....... 45

3.1 Data Flow Model...................... 45

3.2 Listing of Functions.................... 47

4. Application of Forecasting Technique to Large-Area

silicon Sheet Projection................... 51

4.1 Projection of Silicon Sheet Technology Parameters.. 51

4.2 Association Between Technology Capability and Time. 53

4.3 Approach to Parameter Projection.............. 54

4.4 Computer Evaluation................... 57

4.5 Analysis of Results.................... 63

5. Conclusions.......................... 64

6. References............................ 66

FIFTH QUARTER ACTIVITY PLAN.................. 67 
TECHNICAL CONTENT STATEMENT

This report contains information prepared by the International Business Machines Corporation under JPL contract. It́s contents are not necessarily endorsed by the Jet Propulsion Laboratory, California Institute of Technology, or by the National Aeronatics and space Administration. 


\section{RESEARCH PROGRAM PLAN}

OBJECTIVES

1. Technological assessment of ribbon growth of silicon by a capillary action shaping technique.

2. Economic evaluation of ribbon silicon grown by a capillary action shaping technique as low-cost silicon.

SYNOPSIS OF PROGRAM OF STUDY

1. Crystal growth of silicon ribbons.

2. Characterization of silicon ribbons.

3. Economic evaluations and computer-aided simulation of ribbon growth. 
FOURTH QUARTER HIGHLIGHTS

- A new capiliary action shaping technique die was designed. This new die allows improvements in surface smoothness and in SiC surface-particle denstiy.

- Forty-seven ribbons greater than 0.5 meter $10 n g$ and $25 \mathrm{~mm}$ wide were grown during the last quarter.

- Ribbon width was extended to $38 \mathrm{~mm}$ ( $11 / 2$ inches).

- Surface films on ribbon surfaces were analyzed as SiC crystalites. Significant structural differences, depending on the deposition location, were found.

- Epitaxial growth of SiC through preferential incorporation of (111) SiC planes parallel to (111) silicon planes was ldentified as an important mechanism for surface film formation.

- Development of a new technology-forecasting technique was continued. This technique is being applied to projceting th: future cost of energy at the level of silicon-sheet material. From a baseline, future technology capability is profected through full 
maturity. The concept of chronology 18 introduced by estimating the probability of meeting the objective associated with the production-unit parameter and leads to a specific cost-versus-time relationship.

- Silicon-sheet technology was shown to have the potential for achieving future low-cost material objectives for photovoltaic applications, if development milestones defined in this study are met.

o 1980 and 1985 energy-capacity costs of $\$ 750 / \mathrm{kWE}$ and $\$ 350 / \mathrm{kWE}$, respectively, at the level of silicon-sheet material, are projected.

- This analysis confirmed, from a silicon-sheet material standpoint, that ERDA-stated energy-capacity cost obfectives at the array level are achlevable, but with little margin for error. 
CRYSTAL GROWTH

by

T. F. C1szek

1. INTRODUCTION

The crystal-growth method under investigation is a capiliary action shaping technique. Meniscus shaping for the desired ribbon geometry occurs at the vertex of a wettable die. As ribbon growth depletes the melt meniscus, caplilary action supplies replacement material. The configuration of the technique used in our initial studies is shown in Fig. 1 and is similar to the edge-defined, film-fed growth (EFG) process described by LaBelle (1). The crystal-growth method has been applied to sllicon ribbons for several years $(2,3,4)$, and long ribbons up to $25 \mathrm{~mm}$ in width have been produced.

Certaln problems still awatt solution before the technique becomes viable for large-scale economical photovoltalc applications. High-density graphite fulfills the durability and wettability requirements of a die (2) and has been used, to date, for most sllicon rlbbon growth; it is not, however, completely non-reactive. Good crystallographic perfection has been achieved on small ribbon segments $(2,3)$, but the 


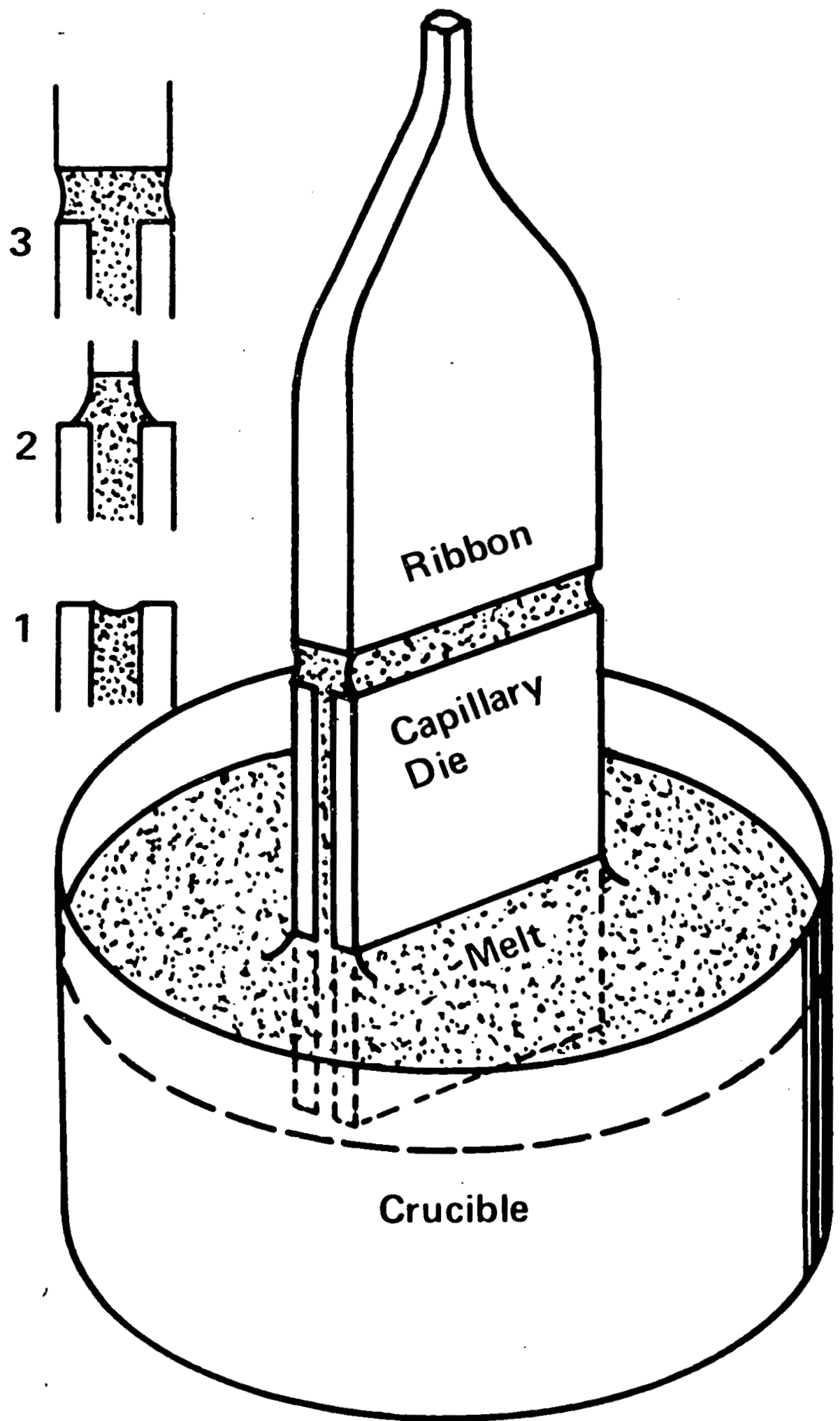

Fig. 1. A schematic diagram of the capillary action shaping technique for silicon ribbon growth. 
structure of large ribbons 18 marred by planar, 11 ne, and point defects. Our objective in this work 18 to attain a clear technological assessment of silicon ribbon growth by the capillary action shaping technique and to enhance the applicability of the technique to photovoltalc power device matertal.

In this report, a new capillary die design is described. It represents a departure from the die types used for edge-defined, film-fed growth, in that the bounding edges of the die top are not parallel or concentric with the growing ribbon. The new dies allow a higher melt meniscus with concomitant improvements in ourface smoothness and freedom from S1C surface particles, which can degrade perfection.

Also in this reporting period, ribbons were grown for delivery to JPL. Twenty ribbons and 30 ribbon samples were shipped. Detalled dimensional characteristics of most ribbons grown during the past year are presented in Append1x 1 .

Finally, our initial progress in the growth of 38 -mm (1-1/2-1nch)-wide ribbono, up to $46 \mathrm{~cm}$ in leuglh, Is reported. 
2. CAPILLARY ACTION SHAPING TECHNIQUE

DIE DESIGN CONSIDERATIONS

The capillary die design used for meniscus shaping in our capiliary action shaping technique of rtbbon growth over the past several months is indicated in Fig. 2. The die 18 a departure from the edge-defined, film-fed technique of crystal growth, in that the cross section of the growing rlbbon is not concentric with the top edges of the die. The die top 18 considerably thicker in the mid-region than at the edges, yet the resultant ribbon 18 flat or somewhat

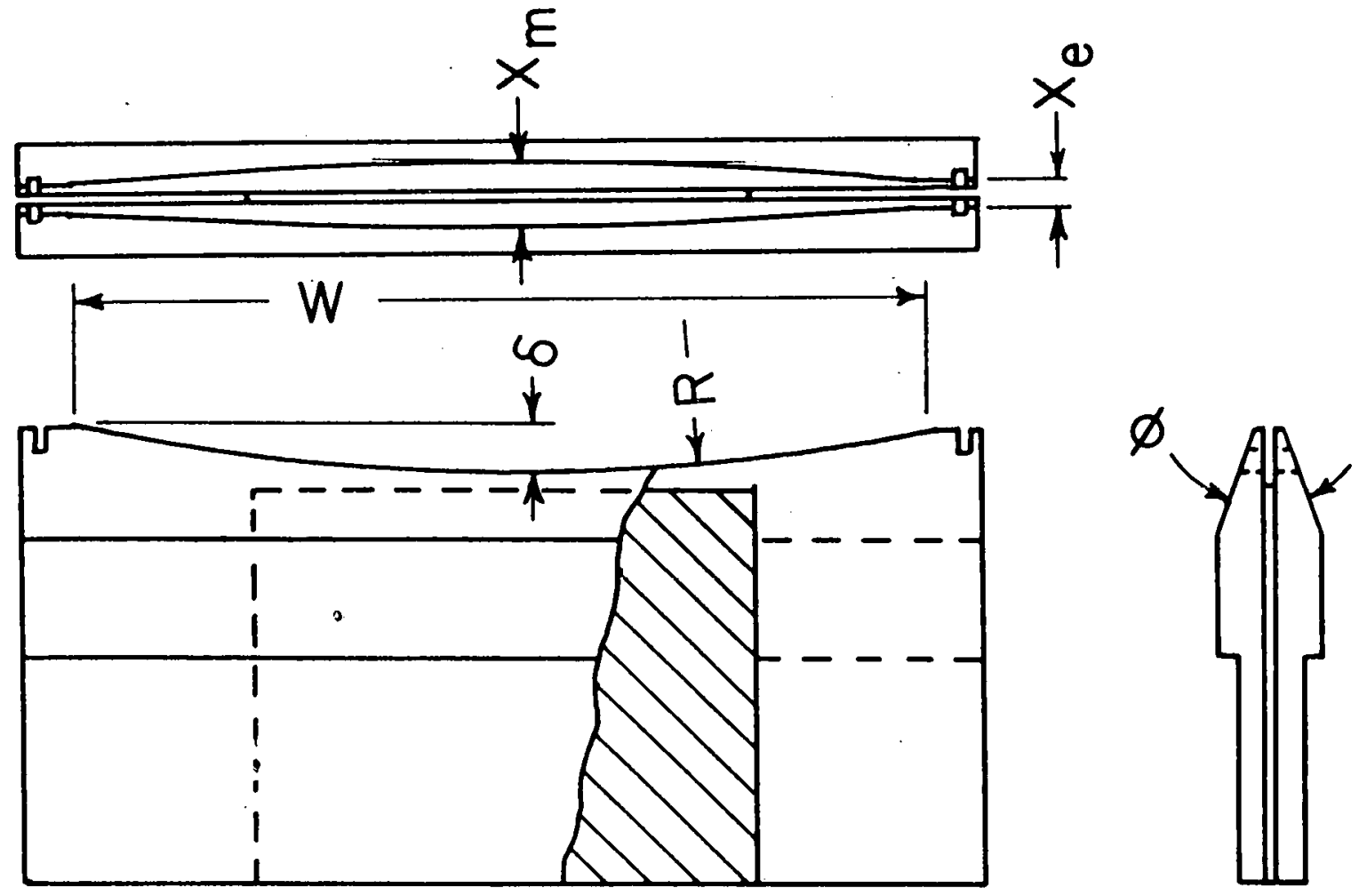

Fig. 2. Die for improved capillary action shaping technique ribbon growth. 
thicker at the edges than in the middle. This die design allows a higher meniscus at the central region of the solidification front and thus reduces problems which can occur when using flat-top dies or curved-top dies with parallel top edges as in the EFG technique. Such problems come about primarily from the fact that the graphite die used for slicon growth slowly dis8olves in the liquid. Carbon-saturated silicon rises up the capiliary slot in the die and comes to the top reglon where ribbon solidification occurs. This top region 18 the coolest region in the growth system. Here, excess carbon 18 forced out of the saturated silicon solution in the form of $B-S 1 C$ crystallites, which tend to collect at the top surface of the die. These crystallites distort the melt meniscus and make the ribbon non-uniform in 1ts surface smoothness. Because of the proximity of the freezing interface to the die top, the SiC particles are frequently incorporated in the ribbon, where they generate dislocations and other defects.

It 18 advantageous to keep the Interface of the freezing ribbon as far as possible from the die top, and this can be accomplished with the structure shown in F1g. 2 . The die top ourface 18 curved so that 1 t 18 higher at the edges than In the middle. In this way, if the ribbon's solid-11quid Interface 18 malntalned approximately planar, then the 
Interface 18 further from the die, at least in the central region. The central region is most critical for generation of defects in the silicon body. However, if the width of the die top is kept constant while the die top surface 18 curved, then a higher meniscus in the central region necessarily implies that the top of the meniscus 18 thinner there. This would cause the ribbon to be very non-uniform In thickness from one edge to the other (1.e., much thinner in the middle than at the ends). Thus, not only should the die top curve downward from the ends toward the central region, but it must also become wider in the central region than at the ends, as in F18. 2. The meniscus, then, has a wider base in the central region. The wider base, combined with the greater menlscus height in the central region, results in a more uniform thickness at the solid-1iquid interface. In summary, there are two things that are important to the die design: one is the curvature of the top surface, and the other 18 the widening of the die top in the central regton.

Plgure 318 a cross section at the center of the die before the seed crystal 18 applied. No through capillary 18 shown because this 18 the area that holds the two major portions of the die together. Flgure $3 b$ shows the edge condition with the ribbon in place, and Figure $3 c 18$ a vertical cross 


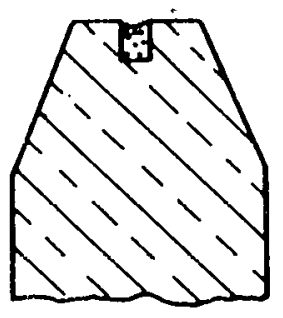

a

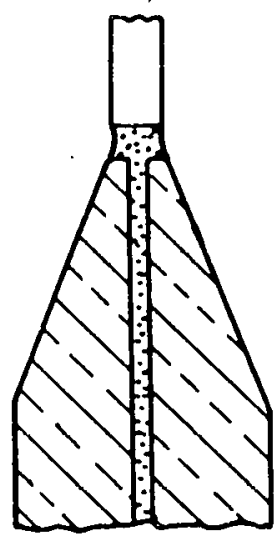

b

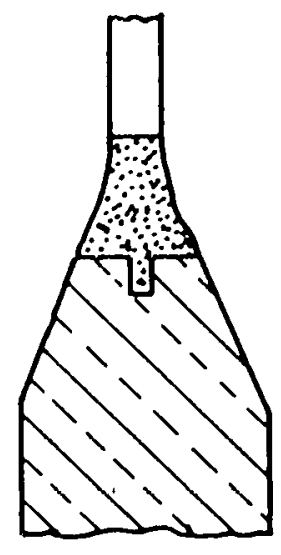

C

Fig. 3. Cross section through die and ribbon: (a) central die top before seeding, (b) near edge of die during growth, and (c) near central region of die top during growth.

section through the central reglon during full-width ribbon growth. It can be seen that, even though the top of the die is narrow at the ends and relatively wide in the middle, the r Ibbon thickness is essentially uniform because the freezing interface 18 close to the die top near the ends of the die, but higher above the die top near the middle. The top of the meniscus is about as wide as the bottom of the mentscus at the end areas (F1g. $3 b)$. However, the cross section of the meniscus near the central pofnt of the die and ribbon (FIg. 3c) tapers from a wide base to a narrow top. By proper cholce of the curvature of the die top and the taper angle of the sides of the die, an optimum value for this variation of the width of the die top with position along the die top can be obtalned. 
The outer edges of the top die surface, that 18, those edges which bound the lower portion of the melt meniscus from which the ribbon solidifies, can be considered to be determined by the intersection of a vertical truncated wedge with enclosed angle- $\phi$, truncated thlckness - $X_{e}$ and width - W, with a horizontal cylinder of radius R. The Intersection is made essentially such that the cylindrical surface contalns the short edges, $x_{e}$, of the wedge top. The resultant die top is that of F18. 2 , where $X_{e} 18$ the top surface thickness at the ends, $X_{m}$ the top surface thickness In the center, $\phi$ the enclosed angle of the tapered wedge, R the radius of curvature of the top surface, W the width of the die, and $\delta$ the difference in helght from ends to center. The top of the die, thus, smoothly increases in thickness from $x_{e}$ to $x_{m}$ and decreases in hefght, by an amount $\delta$, as we go from the die edge to the die middle.

The objective in this design is to attain a high-melt meniscus in the central region, since proximity of the freezing interface to the die top 18 detrimental to ribbon perfection and surface smoothness, while still maintaining the proximity at the die ends to stablize the ribbon width. Furthermore, this must be achleved in a sooth transition to faclitiate the early stages of growth from seed size to full width. 
$R$ and $\phi$ are chosen to optimlze the values of $X_{m}-X_{e}$ and $\delta$ for successful ribbon growth. These parameters are given by

$$
\begin{aligned}
& \delta=R-\frac{W}{2 \tan \left(\sin ^{-1} \frac{W}{2}\right)} \\
& x_{m}-x_{e}=2 \delta \tan \phi / 2 .
\end{aligned}
$$

For the 25-mm-wide ribbons grown recently, dies were constructed with $R=101.6 \mathrm{~mm} ; \phi=40^{\circ}$, and $X_{e}=0.54 \mathrm{~mm}$. Thus, $X_{m}$ was $\sim 0.99 \mathrm{~mm}$. The typical edge thickness and middle thickness of the resultant ribbons were $0.42 \mathrm{~mm}$ and $0.21 \mathrm{~mm}$, respectively; the exact values were dependent upon growth rate. Better surface smoothness and a lower SiC surface-particle density $\left(<0.1 / \mathrm{cm}^{2}\right)$ were seen previously with slightly thicker dies, where $X_{e}$ was $0.79 \mathrm{~mm}$ and $R$ and $\phi$ were as above. These ribbons had a typical edge thickness of $0.64 \mathrm{~mm}$ and a middle thlckness of $0.42 \mathrm{~mm}$. The thickness of the die top in the central region was $1.37 \mathrm{~mm}$ in this case. Although these ribbons have a relatively large deviation from flatness (on the order of $0.1 \mathrm{~mm}$ ), with the edges being thicker than the middle, they are quite smooth on a local scale compared with ribbons grown from an EFG die, as was shown in Fig. 7 of the second quarterly report (5). Local roughness variations of 10- $\mu$ m maximum amplitude have been ehleved with the new die design, whereas roughness variations of about 50- $\mu \mathrm{m}$ maximum 
amplitude were typlcal with the flat top die. silicon carblde particle densities with the new die are typlcally $<0.1 / \mathrm{cm}^{2}$ as compared w1th $5 / \mathrm{cm}^{2}$ for the EFG die.

During this quarter, 25-mm-wide dies with the dimensions Indicated above were used in confunction with our standard growth setup [see pp.7-9 of the third quarterly report (6)] to grow ribbons for delivery to JPL. Forty-seven ribbons, corresponding to a total length of $24 \mathrm{~m}$, were grown. The average length was $0.51 \mathrm{~m}$, the average edge thickness was $0.41 \mathrm{~mm}$, and the average central thickness was $0.27 \mathrm{~mm}$. Twenty complete ribbons and 30 ribbon segments were shipped to JPL. Ribbons as thin as $0.30 \mathrm{~mm}$ at the edge and $0.10 \mathrm{~mm}$ in the central region were produced when pull speeds in excess of $3 \mathrm{~cm} / \mathrm{min}$ were employed. However, these ribbons exhibited a non-flat surface, with undulating bulges of small amplitude. In general, surface roughness, S1C particle density, asymetrical growth, and growth-control requirements were all more severe with dies designed for thin ribbon growth than with dies designed for thicker ribbon growth.

Twelve meters of ribbon. were grown from a single die in 9 melt-down cycles. The die still appeared to be serviceable at this polnt, although ribbon roughness had Increased somewhat because of S1C bulidup at the die top. 


\section{GROWTH OF 38-MM-WIDE RIBBONS}

The concepts discussed relative to 25-mm-wide capillary action shaping technique dies were extended to the design of a die for 38-mm (1-1/2-1nch)-wide ribbons. In this die, $\delta=1.0 \mathrm{~mm}, \phi=50^{\circ}, \mathrm{x}_{\mathrm{e}}=0.44$, and $\mathrm{x}_{\mathrm{m}}=1.16 \mathrm{~mm}$. Three full-width ribbons were grown, the longest of which was $46 \mathrm{~cm}$ at full $(38-\mathrm{mm})$ width (see Fig. 4). The ribbons were grown at speeds of 16-18 mm/min. Typically, the edge thickness was $0.42 \mathrm{~mm}$ and the middle thickness was $0.54 \mathrm{~mm}$. A thinner portion $(0.37 \mathrm{~mm})$ was present, however, between the edge and the middle. Thus the total deviation from flatness was about $0.09 \mathrm{~mm}$. More difficulty was noticed with freeze-out during the process of spreading from seed-width (3-mm) to full-width growth than had been observed during 25-mm-wide ribbon growth. Dies are being fabricated with slightly different dimensional parameters, in hopes of reducing this problem.

The crystallographic defect structure and surface smoothness of the 38-mm-wide ribbons are similar to those seen for 25-mm-wide ribbons. The largest ribbon grown $(3.8 \mathrm{~cm} \times 46 \mathrm{~cm})$ had a $\mathrm{Sic}$ surface-particle density of $0.07 / \mathrm{cm}^{2}$, which is also comparable to densities seen with 25-mm-wide ribbons. 


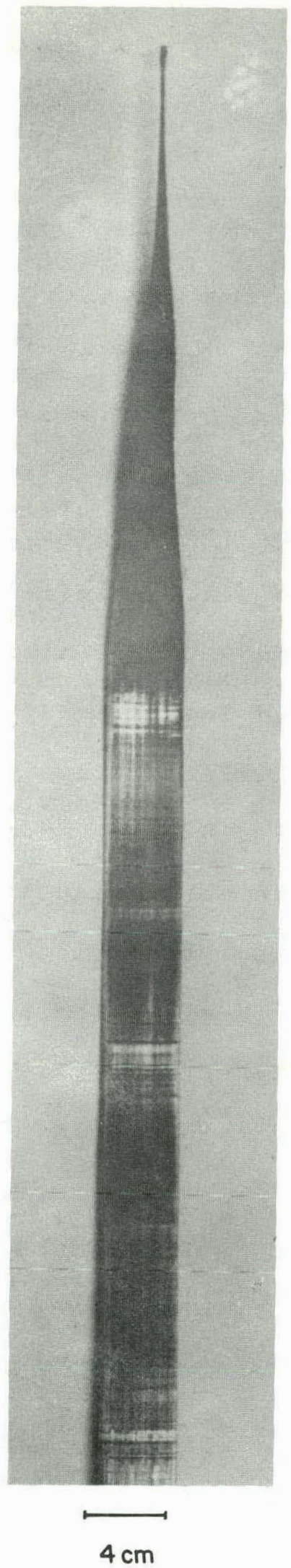

Fig. 4. A 38-mm-wide by $46-\mathrm{cm}$-long silicon ribbon grown by the capillary action shaping technique. 
4. REFERENCES

1. H. E. LaBelle, Jr., Mater. Res. Bull. 6, 581 (1971).

2. T. F. Ciszek, Mater. Res. Bul1. 7,731 (1972).

3. T. F. Ciszek and G. H. Schwuttke, Phys. Status Sol1d1 (a) 27,231 (1975).

4. J. C. Swartz, T. Surek, and B. Chalmers, J. Electron. Mater. 4, 255 (1975).

5. Quarterly Technical Progress Report Number 2, JPL Contract 954144 , G. H. Schwuttke, Principal Investigator, December 15, 1975.

6. Quarterly Technical Progress Report Number 3, JPL Contract 954144, G. H. Schwuttke, Principal Invest1gator, March 15, 1976.

5. ACKNOWLEDGMENT

Technical support in crystal growing was provided by F. Newman. 
Appendix 1

DIMENSIONAL CHARACTERISTICS OF SOME RIBBONS GROWN DURING

AUGUST 1975 - MAY 1976

\begin{tabular}{|c|c|c|c|c|c|c|c|c|c|}
\hline \multirow{3}{*}{$\begin{array}{l}\text { Ribbon } \\
\text { Run No. }\end{array}$} & \multicolumn{2}{|c|}{ Seed } & \multicolumn{3}{|l|}{ Usable } & \multicolumn{4}{|c|}{ Thickness (mm) } \\
\hline & \multirow{2}{*}{\multicolumn{2}{|c|}{$\begin{array}{l}\text { Orientation } \\
\text { Axis Surface } \\
\end{array}$}} & \multirow{2}{*}{$\begin{array}{l}\text { Length } \\
(\mathrm{cm}) \\
\end{array}$} & \multicolumn{2}{|c|}{ Width (mm) } & \multicolumn{2}{|c|}{ Seed } & \multicolumn{2}{|c|}{ Tail } \\
\hline & & & & Max & Min & Max & $\underline{\text { Min }}$ & $\underline{\operatorname{Max}}$ & Min \\
\hline 50805 & 0 & 0 & 38 & 8.6 & 6.7 & 1.01 & .00 & 1.03 & .00 \\
\hline 50806 & 0 & 0 & 65 & 8.1 & 6.2 & 1.00 & .00 & 1.05 & .00 \\
\hline 50807 & 0 & 0 & 25 & 8.7 & 7.6 & 1.10 & .00 & 1.15 & .00 \\
\hline 50808 & 0 & 0 & 34 & 8.4 & 8.1 & 1.06 & .00 & 1.21 & .00 \\
\hline 50809 & 0 & 0 & 114 & 7.3 & 6.7 & 1.01 & .00 & 1.05 & .00 \\
\hline 50811 & 0 & 0 & 28 & 8.0 & 7.1 & 1.35 & .00 & 1.35 & .00 \\
\hline 50825 & 0 & 0 & 32 & 4.7 & 4.2 & 1.58 & .00 & 1.60 & .00 \\
\hline 50826 & 0 & 0 & 32 & 5.5 & 3.8 & 1.25 & .00 & 1.43 & .00 \\
\hline 50909 & 0 & 0 & 23 & 26.2 & 25.8 & .70 & .35 & .67 & .39 \\
\hline 50911 & 110 & 111 & 24 & 25.7 & 24.4 & .65 & .35 & .62 & .41 \\
\hline 50916 & 110 & 100 & 46 & 26.0 & .0 & .73 & .54 & .62 & .33 \\
\hline 50919 & 110 & 100 & 90 & 26.0 & .0 & .55 & .23 & .65 & .36 \\
\hline 50926 & 110 & 100 & 18 & 26.0 & .0 & .65 & .57 & .65 & .56 \\
\hline 50927 & 110 & 100 & 40 & 26.0 & .0 & .53 & .40 & .54 & .34 \\
\hline 50928 & 110 & 100 & 45 & 26.0 & .0 & .49 & .32 & .50 & .31 \\
\hline 51003 & 110 & 112 & 49 & 25.6 & 23.6 & .67 & .51 & .63 & .46 \\
\hline 51005 & 110 & 112 & 50 & 26.1 & 24.7 & .63 & .44 & .66 & .45 \\
\hline 51007 & 110 & 112 & 51 & 26.4 & 23.0 & .75 & .53 & .73 & .45 \\
\hline 51008 & 110 & 112 & 44 & 25.6 & 23.7 & .63 & .40 & .66 & .43 \\
\hline 51012 & 100 & 110 & 91 & 25.9 & 24.3 & .69 & .49 & .68 & .47 \\
\hline 5101.3 & 100 & 110 & 20 & 26.0 & 25.0 & .64 & .42 & .68 & .51 \\
\hline 5101,4 & 100 & 110 & 54 & 25.7 & 21.2 & .69 & .62 & .62 & .34 \\
\hline 51015 & 110 & 100 & 84 & 25.1 & 23.4 & .61 & .35 & .64 & .34 \\
\hline 51016 & 110 & 100 & 52 & 24.8 & 17.0 & .73 & .48 & .60 & .39 \\
\hline 51017 & 110 & 100 & 22 & 24.7 & 23.8 & .64 & .45 & .44 & .26 \\
\hline 51018 & 110 & 100 & 23 & 25.1 & 25.0 & .72 & .43 & .67 & .41 \\
\hline 51019 & 110 & 100 & 56 & 25.0 & 23.6 & .67 & .44 & .55 & .35 \\
\hline 51021 & 110 & 100 & 54 & 26.2 & 24.4 & .65 & .49 & .66 & .38 \\
\hline 51022 & 110 & 100 & 63 & 25.6 & 23.8 & .63 & .38 & .59 & .28 \\
\hline 51023 & 110 & 100 & 63 & 25.5 & 24.1 & .62 & .35 & .59 & .39 \\
\hline 51024 & 110 & 100 & 24 & 26.2 & 12.5 & .63 & .35 & .64 & .26 \\
\hline 51025 & 110 & 100 & 58 & 25.7 & 23.3 & .54 & .31 & .56 & .22 \\
\hline 51026 & 110 & 100 & 62 & 25.4 & 24.6 & .62 & .42 & .62 & .37 \\
\hline 51027 & 110 & 100 & 59 & 24.9 & 24.5 & .51 & .29 & .52 & .26 \\
\hline 51102 & 110 & 112 & 12 & .0 & .0 & .00 & .00 & .00 & .00 \\
\hline 51104 & 110 & 100 & 59 & 25.3 & 23.5 & .54 & .40 & .51 & .36 \\
\hline
\end{tabular}




\begin{tabular}{|c|c|c|c|c|c|c|c|c|c|}
\hline \multirow{3}{*}{$\begin{array}{l}\text { Ribbon } \\
\text { Run No. }\end{array}$} & \multicolumn{2}{|c|}{ Seed } & \multirow{3}{*}{$\begin{array}{l}\text { Usable } \\
\text { Length } \\
\text { (cm) }\end{array}$} & \multirow{2}{*}{\multicolumn{2}{|c|}{ Width (mm) }} & \multicolumn{4}{|c|}{ Thickness (mm) } \\
\hline & Orie & atation & & & & \multicolumn{2}{|c|}{ Seed } & \multicolumn{2}{|c|}{ Tail } \\
\hline & Axis & Surface & & Max & Min & $\underline{\operatorname{Max}}$ & Min & Max & Min \\
\hline 51107 & 110 & 112 & 49 & 25.5 & 24.1 & .45 & .29 & .50 & .28 \\
\hline 51110 & 110 & 100 & 10 & 25.7 & 23.3 & .55 & .50 & .55 & .50 \\
\hline 51114 & 110 & 100 & 48 & 25.4 & 24.4 & .50 & .36 & .50 & .34 \\
\hline 51115 & 110 & 100 & 87 & 25.6 & 25.2 & .46 & .30 & .57 & .35 \\
\hline 51118 & 110 & 100 & 57 & 25.2 & 24.8 & .46 & .31 & .45 & .29 \\
\hline 51119 & 110 & 100 & 54 & 24.7 & 24.5 & .43 & .28 & .46 & .29 \\
\hline 51120 & 110 & 100 & 21 & 24.9 & 23.8 & .45 & .32 & .47 & .25 \\
\hline 51201 & 110 & 100 & 16 & 24.6 & 17.4 & .47 & .50 & .50 & .35 \\
\hline 51202 & 110 & 100 & 60 & 25.0 & 24.1 & .52 & .42 & .50 & .45 \\
\hline 51203 & 110 & 100 & 19 & 25.5 & 24.1 & .76 & .50 & .45 & .36 \\
\hline 51205 & 110 & 100 & 36 & 25.0 & 24.9 & .55 & .45 & .50 & .45 \\
\hline 51207 & 110 & 100 & 20 & 24.5 & 22.2 & .61 & .40 & .26 & .22 \\
\hline 51208 & 110 & 100 & 46 & 24.6 & 24.3 & .50 & .40 & .46 & .36 \\
\hline 51209 & 110 & 112 & 53 & .0 & .0 & .45 & .35 & .00 & .00 \\
\hline 51210 & 110 & 112 & 46 & 24.9 & 20.6 & .67 & .50 & .65 & .50 \\
\hline 51,213 & 110 & 112 & 32 & 23.5 & 14.0 & .38 & .32 & .53 & .40 \\
\hline 51214 & 110 & 100 & 55 & 24.8 & 23.2 & .48 & .40 & .45 & .41 \\
\hline 51216 & 110 & 100 & 39 & 25.3 & 22.7 & .71 & .52 & .73 & .45 \\
\hline 51217 & 110 & 100 & 57 & 24.7 & 23.4 & .74 & .48 & .75 & .47 \\
\hline 51218 & 110 & 100 & 45 & 22.9 & 22.4 & .55 & .50 & .60 & .50 \\
\hline 60102 & 110 & 100 & 56 & 25.5 & 24.9 & .53 & .39 & .50 & .33 \\
\hline 60103 & 110 & 100 & 51 & 25.2 & 24.2 & .48 & .31 & .45 & .27 \\
\hline 60104 & 110 & 112 & 60 & 25.4 & 24.3 & .49 & .29 & .52 & .33 \\
\hline 60105 & 110 & 100 & 58 & 24.9 & 18.8 & .50 & .45 & .50 & .45 \\
\hline 60110 & 110 & 100 & 46 & 24.8 & 23.6 & .53 & .42 & .50 & .37 \\
\hline 60111 & 110 & 100 & 94 & 25.4 & 23.8 & .00 & .00 & .00 & .00 \\
\hline 60112 & 110 & 100 & 90 & 24.9 & 23.4 & .45 & .35 & .50 & .27 \\
\hline 60114 & 110 & 100 & 33 & 25.4 & 22.7 & .50 & .45 & .53 & .36 \\
\hline 60115 & 110 & 100 & 36 & 25.2 & 20.1 & .50 & .40 & .40 & .30 \\
\hline 60116 & 110 & 100 & 31 & 25.2 & 22.4 & .53 & .42 & .37 & .28 \\
\hline 60119 & 110 & 100 & 28 & 25.4 & 25.1 & .55 & .50 & .54 & .38 \\
\hline 60120 & 110 & 100 & 95 & .0 & .0 & .00 & .00 & .00 & .00 \\
\hline 60202 & 110 & 100 & 96 & 24.6 & 23.7 & .50 & .32 & .47 & .30 \\
\hline 60203 & 110 & 100 & 25 & 25.5 & 22.2 & .57 & .38 & .55 & .25 \\
\hline 60206 & 110 & 100 & 9 & 23.1 & 18.1 & .62 & .70 & .60 & .64 \\
\hline 60209 & 110 & 100 & 45 & 25.9 & 24.2 & .80 & .90 & .64 & .90 \\
\hline 60212 & 110 & 111 & 55 & 25.7 & 25.1 & .60 & .50 & .60 & .40 \\
\hline 60213 & 110 & 111 & 77 & 25.6 & 25.4 & .60 & .85 & .00 & .00 \\
\hline 60216 & 110 & 100 & 40 & 24.6 & 24.2 & .70 & .80 & .55 & .65 \\
\hline 60217 & 110 & 100 & 18 & 24.4 & 24.2 & .60 & .85 & .42 & .52 \\
\hline 60303 & 110 & 111 & 55 & 24.9 & 22.5 & .47 & .43 & .45 & .35 \\
\hline 60304 & 100 & 110 & 55 & 25.5 & 22.6 & .45 & .42 & .42 & .22 \\
\hline 60309 & 100 & 110 & 53 & 25.6 & 23.4 & .47 & .50 & .42 & .45 \\
\hline 60310 & 100 & 110 & 23 & 25.2 & 23.9 & .35 & .35 & .38 & .40 \\
\hline 60312 & 111 & 110 & 41 & 24.7 & 21.7 & .32 & .32 & .35 & .37 \\
\hline 60318 & 100 & 110 & 44 & 25.6 & 23.7 & .44 & .40 & .45 & .37 \\
\hline 60320 & 100 & 110 & 55 & 25.3 & 24.3 & .42 & .38 & .36 & .30 \\
\hline 60322 & 111 & 112 & 57 & 24.7 & 24.0 & .40 & .34 & .41 & .25 \\
\hline
\end{tabular}


Seed Usable

Ribbon Orientation Length

Run No. Axis Surface

$60323 \quad 111 \quad 112$

$60324 \quad 111 \quad 112$

$60325 \quad 110 \quad 100$

$60326 \quad 110 \quad 100$

$60328 \quad 110 \quad 100$

$60329 \quad 110 \quad 112$

$60330 \quad 110 \quad 112$

$60337 \quad 100 \quad 110$

$60341 \quad 100 \quad 110$

$60401 \quad 100 \quad 110$

$60402 \quad 100 \quad 110$

$60404 \quad 110 \quad 100$

$60406 \quad 100 \quad 110$

$60407 \quad 100 \quad 110$

$60408 \quad 100 \quad 110$

$60409 \quad 100 \quad 110$

$60414 \quad 110 \quad 100$

$60416 \quad 100 \quad 110$

$60418 \cdot 121 \quad 111$

$60419 \quad 121 \quad 111$

$60420 \quad 121 \quad 111$

$60421 \quad 121 \quad 101$

$60422 \quad 121 \quad 101$

$60432 \quad 100 \quad 110$

$60436 \quad 100 \quad 110$

$60437 \quad 121 \quad 111$

$60438 \quad 121 \quad 111$

$60439 \quad 121 \quad 111$

$60440 \quad 121 \quad 111$

$60442 \quad 121 \quad 111$

$60443 \quad 121 \quad 111$

$60444 \quad 121 \quad 111$

$60446 \quad 100 \quad 110$

$6044,7121 \quad 111$

$60448 \quad 121 \quad 101$

$60506 \quad 100 \quad 110$

$60511 \quad 110 \quad 112$

$60520 \quad 110 \quad 112$

$60521 \quad 121 \quad 101$

$60522 \quad 110 \quad 112$

$60523 \quad 110 \quad 112^{\circ}$

$\begin{array}{lll}60525 & 121 & 101\end{array}$

$60526 \quad 110 \quad 112$

$60527 \quad 110 \quad 112$
Width (mm)

\begin{tabular}{l} 
(cm) \\
\hline 29 \\
54 \\
18 \\
38
\end{tabular}

35

56

43

52

55

56

57

76

56

56

56

48

56

58

54

56

32

50

52

55

52

55

43

54

56

16

38

39

56

58

53

46

36

58

91

90

63

55

58

81
Thickness ( $\mathrm{mm}$ )

Seed Tail

Max $\quad$ Min $\quad$ Max $\quad$ Min $\quad$ Max $\quad$ Min

$\begin{array}{llllll}24.6 & 22.0 & .30 & .27 & .32 & .22\end{array}$

$\begin{array}{llllll}24.4 & 22.2 & .35 & .28 & .32 & .24 \\ 23.9 & 18.6 & .65 & .70 & 50 & .40\end{array}$

$\begin{array}{llllll}23.9 & 18.6 & .65 & .70 & .50 & .40 \\ 25.5 & 21.9 & .45 & .38 & .54 & .46\end{array}$

$\begin{array}{llllll}25.3 & 25.0 & .45 & .42 & .40 & .28\end{array}$

$\begin{array}{llllll}24.8 & 22.7 & .30 & .25 & .40 & .28\end{array}$

$\begin{array}{llllll}25.4 & 24.7 & .30 & .26 & .38 & .30\end{array}$

$\begin{array}{llllll}25.2 & 18.0 & .40 & .27 & .50 & .22\end{array}$

$\begin{array}{llllll}25.1 & 23.7 & .40 & .35 & .48 & .32\end{array}$

$\begin{array}{llllll}26.2 & 25.8 & .50 & .35 & .50 & .37\end{array}$

$\begin{array}{llllll}25.7 & 25.2 & .45 & .32 & .45 & .30\end{array}$

$\begin{array}{llllll}26.4 & 24.6 & .40 & .21 & .50 & .32\end{array}$

$\begin{array}{llllll}25.8 & 25.0 & .52 & .36 & .52 & .24\end{array}$

$\begin{array}{llllll}.0 & .0 & .00 & .00 & .00 & .00\end{array}$

$\begin{array}{llllll}25.0 & 24.2 & .30 & .16 & .30 & .15\end{array}$

$\begin{array}{llllll}24.8 & 23.7 & .30 & .15 & .35 & .10\end{array}$

$\begin{array}{llllll}25.6 & 25.0 & .45 & .25 & .35 & .20\end{array}$

$\begin{array}{llllll}25.4 & 23.6 & .45 & .22 & .38 & .18\end{array}$

$\begin{array}{llllll}25.4 & 20.5 & .45 & .22 & .35 & .10\end{array}$

$\begin{array}{llllll}25.2 & 24.5 & .40 & .22 & .32 & .10\end{array}$

$\begin{array}{llllll}25.2 & 25.0 & .32 & .19 & .35 & .15\end{array}$

$\begin{array}{llllll}25.2 & 22.4 & .48 & .37 & .48 & .32\end{array}$

$\begin{array}{llllll}25.0 & 23.1 & .45 & .25 & .43 & .25\end{array}$

$\begin{array}{llllll}24.9 & 24.7 & .40 & .30 & .00 & .00\end{array}$

$\begin{array}{llllll}24.8 & 24.1 & .48 & .41 & .00 & .00\end{array}$

$\begin{array}{llllll}25.2 & 24.1 & .40 & .28 & .45 & .32\end{array}$

$\begin{array}{llllll}25.0 & 22.9 & .35 & .23 & .28 & .18\end{array}$

$\begin{array}{llllll}25.5 & 24.1 & .45 & .29 & .42 & .30\end{array}$

$\begin{array}{llllll}24.5 & 24.3 & .40 & .25 & .39 & .24\end{array}$

$\begin{array}{llllll}24.4 & 23.1 & .42 & .27 & .42 & .25\end{array}$

$\begin{array}{llllll}24.3 & 20.5 & .40 & .32 & .36 & .16\end{array}$

$\begin{array}{llllll}24.4 & 24.3 & .42 & .19 & .45 & .20\end{array}$

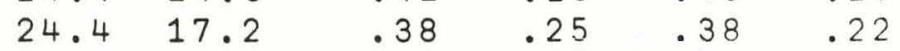

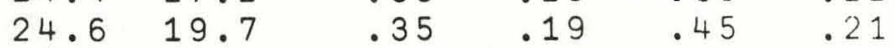

$\begin{array}{llllll}24.4 & 24.1 & .45 & .20 & .40 & .15\end{array}$

$\begin{array}{llllll}38.2 & 37.8 & .55 & .65 & .50 & .65\end{array}$

$\begin{array}{llllll}39.2 & 37.4 & .43 & .55 & .44 & .53\end{array}$

$\begin{array}{llllll}25.2 & 25.0 & .52 & .45 & .51 & .45\end{array}$

$\begin{array}{llllll}24.7 & 22.7 & .40 & .38 & .40 & .28\end{array}$

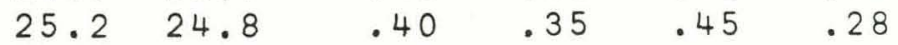

$\begin{array}{llllll}24.7 & 24.5 & .42 & .30 & .39 & .30\end{array}$

$\begin{array}{llllll}24.7 & 24.6 & .45 & .40 & .45 & .40\end{array}$

$\begin{array}{llllll}24.6 & 23.3 & .40 & .20 & .40 & .25\end{array}$

$\begin{array}{llllll}25.0 & 24.3 & .40 & .20 & .50 & .25\end{array}$

A O.O ENTRY INDICATES NO MEASUREMENT WAS MADE. 


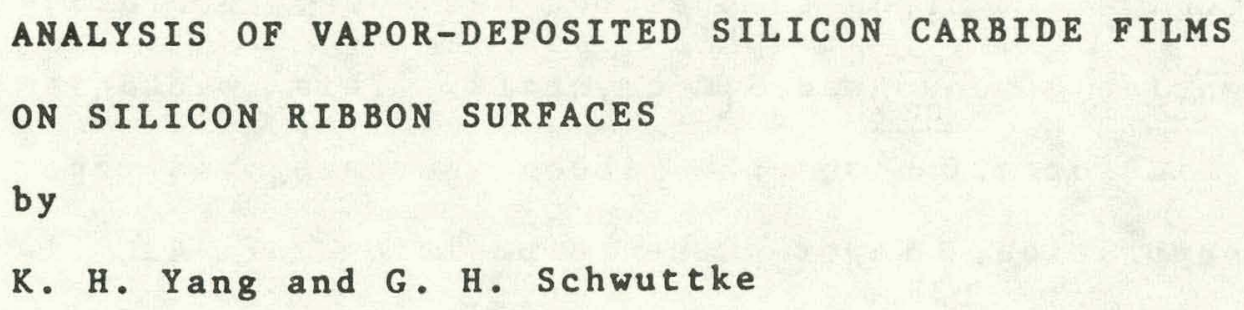

The growth of perfect single-crystal silicon ribbons through the capillary action shaping technique by use of carbon dies is complicated by the formation of SiC during ribbon growth. As shown in the first quarterly report (1), frequently, small Sic crystals form in the orifice of the die. The carbide growth is the result of liquid transport of dissolved carbon from hot regions - submersed die - where the equilibrium carbon concentration is relatively high to the cold regions - die top - where it is lower. Thus a carbon supersaturation occurs at the die top. This supersaturation at the die top is enhanced through carbon rejection at the growth interface and is relieved through carbide growth. Sometimes, crystallites get detached from the die and float in the meniscus at the top of the die. Frequently, small crystals attach to the silicon ribbon during growth, thus destroying the perfection of the crystal. 
This report draws attention to a second mechanism operative in the formation of unwanted Sic crystals. This mechanism is based on SiC formation on the ribbon surface via vapor transport deposition. Vapor-phase deposition of SiC is particularly active during the seeding phase and during the initial growth period, leading to a more or less dense SiC film on the ribbon surface. Such Sic films influence destructively the efficiency of ribbon solar cells. To minimize film formation it is important to understand the crystallographic nature of the f1lm as well as 1 ts mechanism of growth. This report relates to these problems and presents a complete analysis of such films.

2. ANALYSIS OF SURFACE FILMS ON RIBBONS

Visual inspection of seed-ribbon crystals as grown reveals that the seed is covered with a dull bluish film while the surface of the ribbon close to the interface looks dull and dark. The surface duliness decreases rapldy with the distance from the interface, and a shiny ribbon surface is normally obtalned after $10 \mathrm{~cm}$ of ribbon growth. The surface film formation is more pronounced for lower growth speeds and very stong during the seeding operation because of the longer residence time of the seed. In the following, such surface films on ribbons are analyzed through optical and electron transision microscopy. 
3. OPTICAL MICROSCOPY OF SURFACE FILMS

The variation of surface-tilm morphology with distance $s$ from the seed-ribbon incerface is shown in the photomicrographs of Figs. 1a to 1f. Figures la and $1 \mathrm{~b}$ show the film structure on the seed and on the ribbon, above and below the interface. No particular features are resolved optically. The film covers the silicon surface completely. With increasing distance from the interface, the ribbon surface is covered less completely and the optical microscope reveals well-developed dendritic crystal structures covering the ribbon surface. The number of dendrites on the ribbon surface decreases rapidly with increasing distance $s$ from the interface. Note the preferential nucleation of dendrites in grain boundaries, shown in Figs. Id and le. Twin boundaries do not act as preferential nucleation sites, shown in Fig. If. Single 1solated dendrites may form during successive ribbon growth, particularly if a change in growth speed occurs.

4. TRANSMISSION ELECTRON MICROSCOPY OF SURFACE FILMS

Optical microscopy cannot ldentify the crystallographic nature of the films. Therefore, a transmission electron 

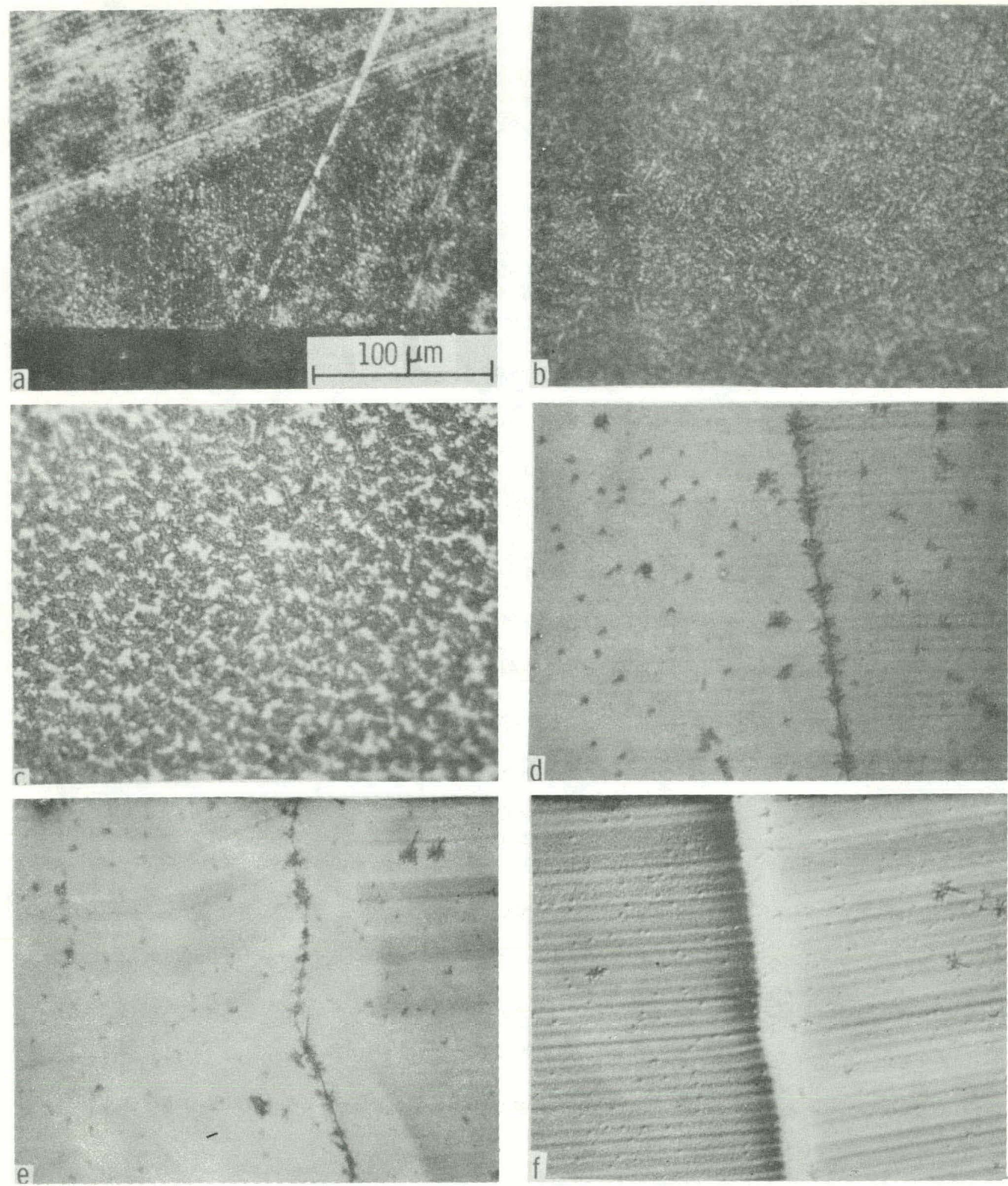

Fig. 1. Optical micrographs showing (a) $\beta-\mathrm{SiC}$ film on seed surface, (b) unresolvable morphology of dull surface at $s \approx 2 \mathrm{~mm}$, well-defined dendrites, (c) at $s \approx 1 \mathrm{~cm}$, (d) at $s \approx 7 \mathrm{~cm}$, (e) at $s \approx 10 \mathrm{~cm}$, and $(f)$ at $s \approx 20 \mathrm{~cm}$. Note that the density of dendrites decreases with increasing $s$. 
microscopy analysis was made. For this purpose, 3-mm-diameter specimens were cut ultrasonically out of seed and ribbon crystals at different locations. The specimens were jet-etched, using a mixture of $\mathrm{HNO}_{3} / \mathrm{HF}$. Before etching, the specimens were thinned by mechanical lapping (on one side only), mainly for film removal. Subsequently, the jet etch was applied to the lapped side until the specimen was thin enough for electron beam penetration. It was noted that the surface film was very resistant to the etch. Consequently, it was easy to etch holes into the silicon and thus isolate the film for transmission electron microscopy work. Figure 2 shows some typical results for the films covering the seed section. Figure $2 a$ is a transmission electron micrograph of a seed specimen. Note the square structure of the silicon holes typical for the $(100)$ orientation of the seed face. Figure $2 b$ is the corresponding electron diffraction pattern, and Fig. 2 c gives the aperture-limited dark-field picture obtained at position A indicated in Fig. 2b. The diffraction patern (F1g. 2b) is analyzed as $B-S 1 C$. The results are summarized in Table I. The dark-field analysis (Fig. 2c) indicates that the film consists of randomiy orlented crystallites. The size of these crystallites ranges approximately from 700 to $1500 \AA$. 


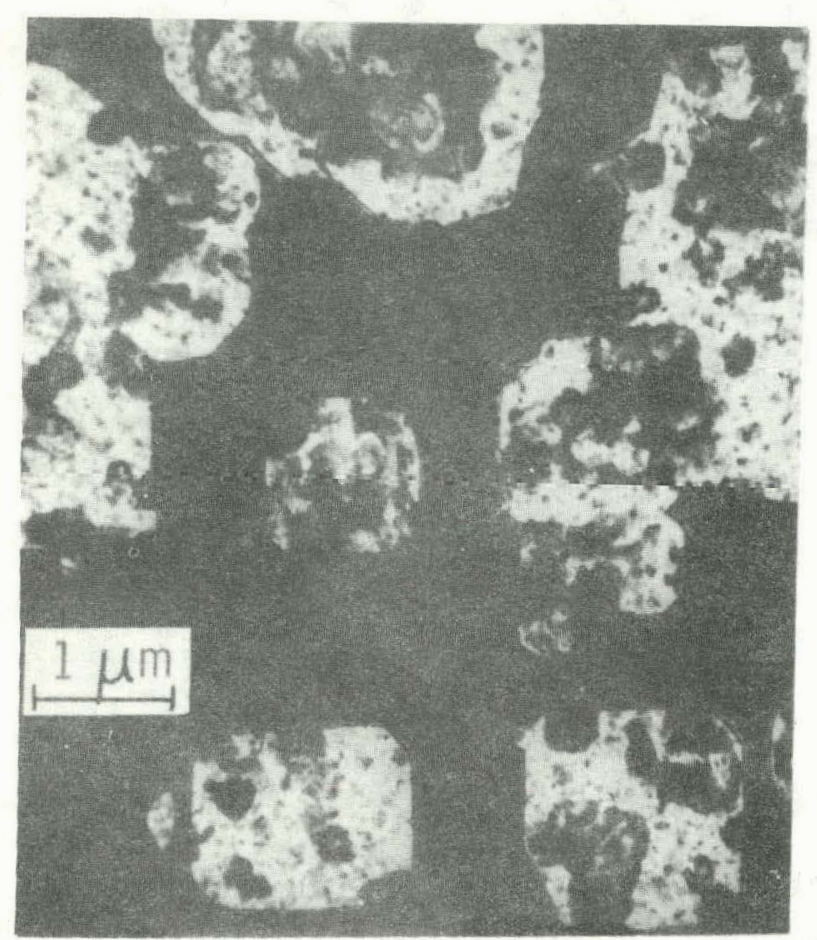

a

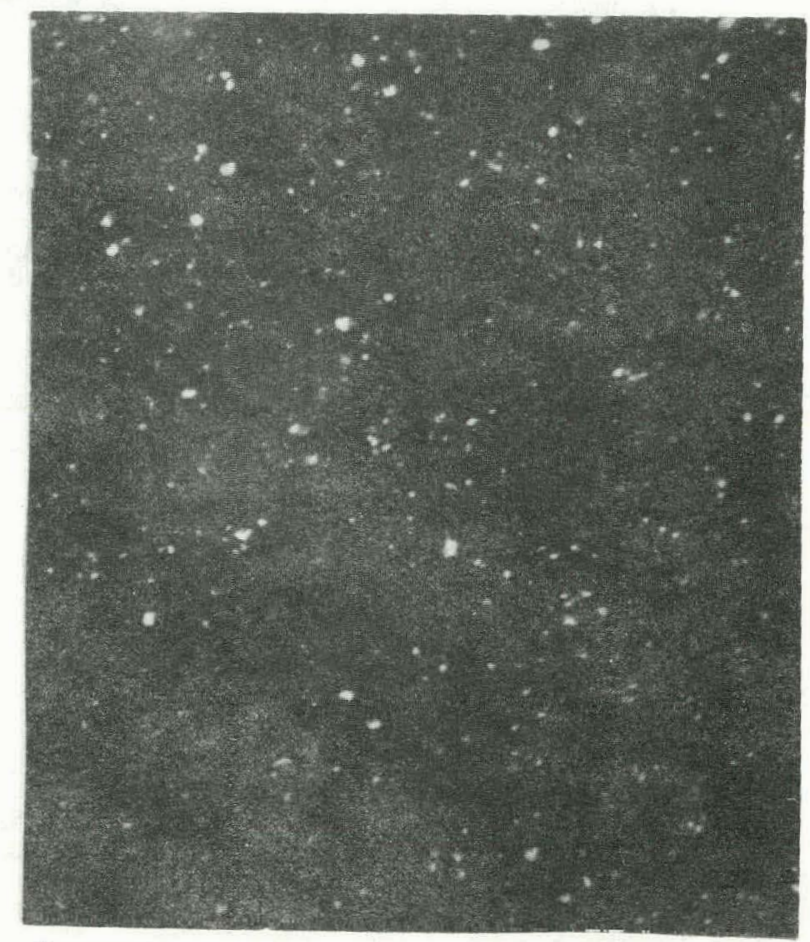

b

C

Fig. 2. TEM micrographs showing (a) $\beta$-SiC film on (001) seed surface, (b) electron diffraction pattern of (a), and (c) dark-field image taken from $A$ in (b). 
TABLE I. Identification of Surface Film on Crystal Seed

\begin{tabular}{lll}
$\begin{array}{l}\text { Surface Film } \\
\text { d, }\end{array}$ & $\begin{array}{l}\text { Reflection } \\
\text { HKL }\end{array}$ & $\begin{array}{l}\text { ASTM } \\
\text { d, }\end{array}$ \\
\hline 2.510 & 111 & 2.51 \\
2.173 & 200 & 2.17 \\
1.541 & 220 & 1.54 \\
1.298 & 311 & 1.31 \\
1.258 & 222 & 1.26 \\
1.089 & 400 & 1.09 \\
0.999 & 331 & 1.00 \\
0.972 & 420 & 0.97 \\
0.888 & 422 & 0.89 \\
0.837 & 333,511 & 0.84 \\
0.767 & 440 & 0.77 \\
0.733 & 531 & 0.74 \\
\hline
\end{tabular}

Similar transmission electron micrographs of specimens taken from the ribbon at positions close to the interface indicate that the surface film on the ribbon also consists of Sic crystals. However, the crystallite size is approximately $1 \mu \mathrm{m}$. Examples of such crystallites are given in Figs. $3 a-c$. Figure $3 a$ is a standard bright-field micrograph, while Fig. $3 b$ is the corresponding dark-field picture obtained by placing the "limited" aperture at a section of the (111) SiC ring (F1g. 3C). This result 


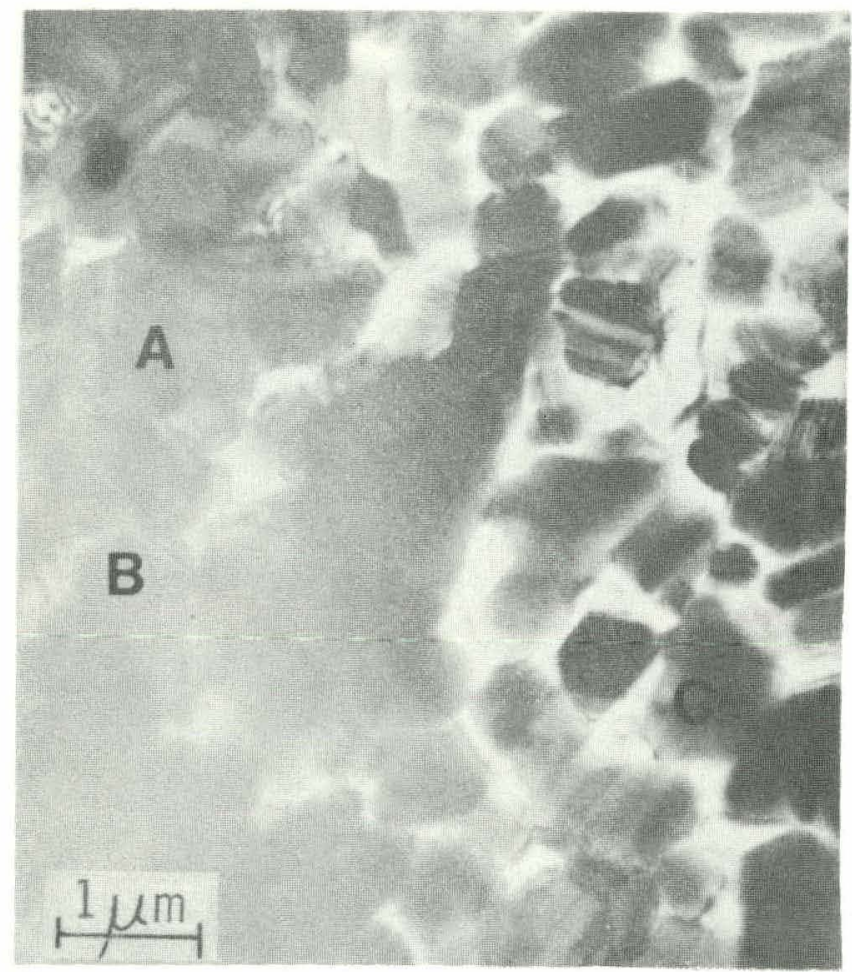

a

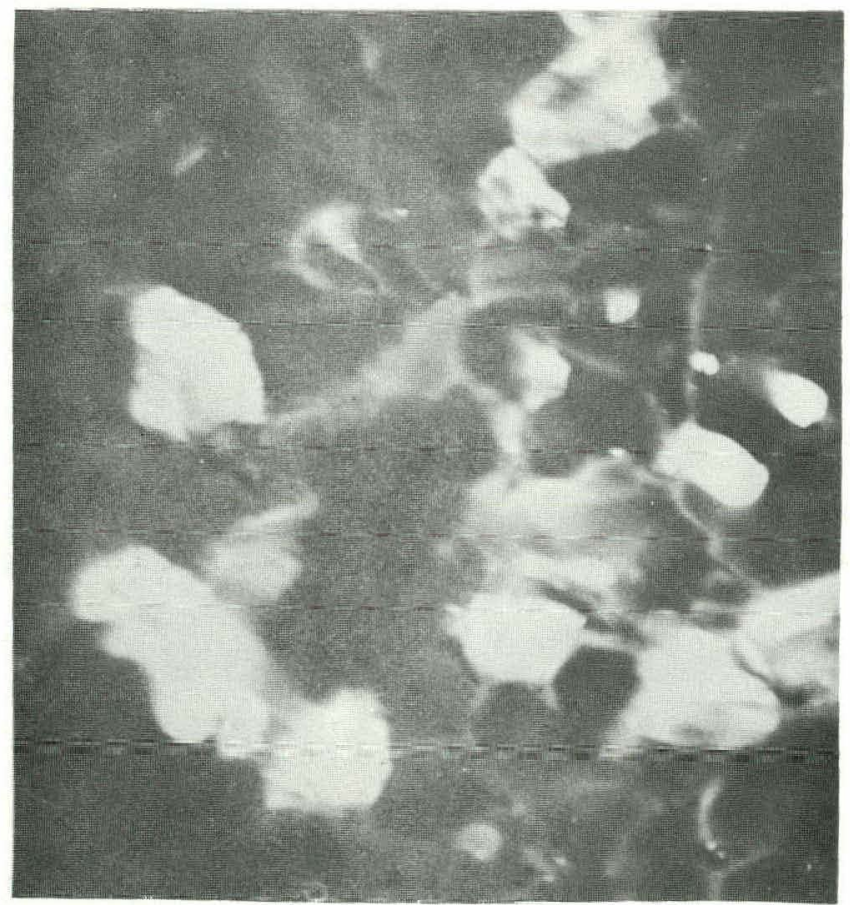

b

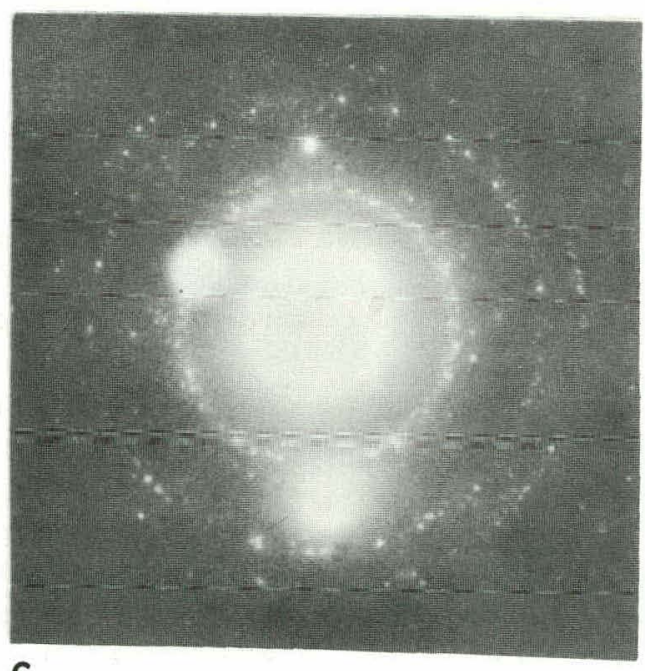

C

Fig. 3. TEM micrographs showing (a) the bright-field image, (b) the dark-field image of $\beta$-SiC particles on ribbon surface close to seed-ribbon interface, (c) corresponding electron diffraction pattern. 
identifies the grains marked A, B, and C in Fig. $3 a$ as B-SiC. Moving the aperture around the (111) SiC ring to different positions causes crystallites of different orientation to show up successively in the corresponding micrographs. From such observations it follows that the film consists of randomly oriented $B$-S1C crystals.

Interesting and instructive results are obtained through the transmission electron microscopy analysis of the dendritic structures. Dendritic structures on ribbon surfaces have been found for growth rates of $12 \mathrm{~mm} / \mathrm{min}$ to $30 \mathrm{~mm} / \mathrm{min}$. The dendrites occur randomly over the ribbon surface or preferentially along grain boundaries, and are of submicron size for faster growth rates. Consequently, they may not yield to optical inspection. The dendrites have been found to Influence generation lifetime of the silicon ribbon surfaces. A detalled investigation of their influence on generation lifetime in silicon ribbons is in progress.

The transmission electron micrographs of a dendritic cluster in bright and dark fields are shown in Figs. $4 a$ and b. The corresponding transmission electron diffraction pattern is presented in Fig. 5a; the diffraction pattern is reproduced schematically in P1g. Sb. The diffraction pattern of Fig. 5a contains the basic [001] silicon diffraction patern, but, in addition, every silicon reflex is surrounded by characteristic satellite reflexes. 


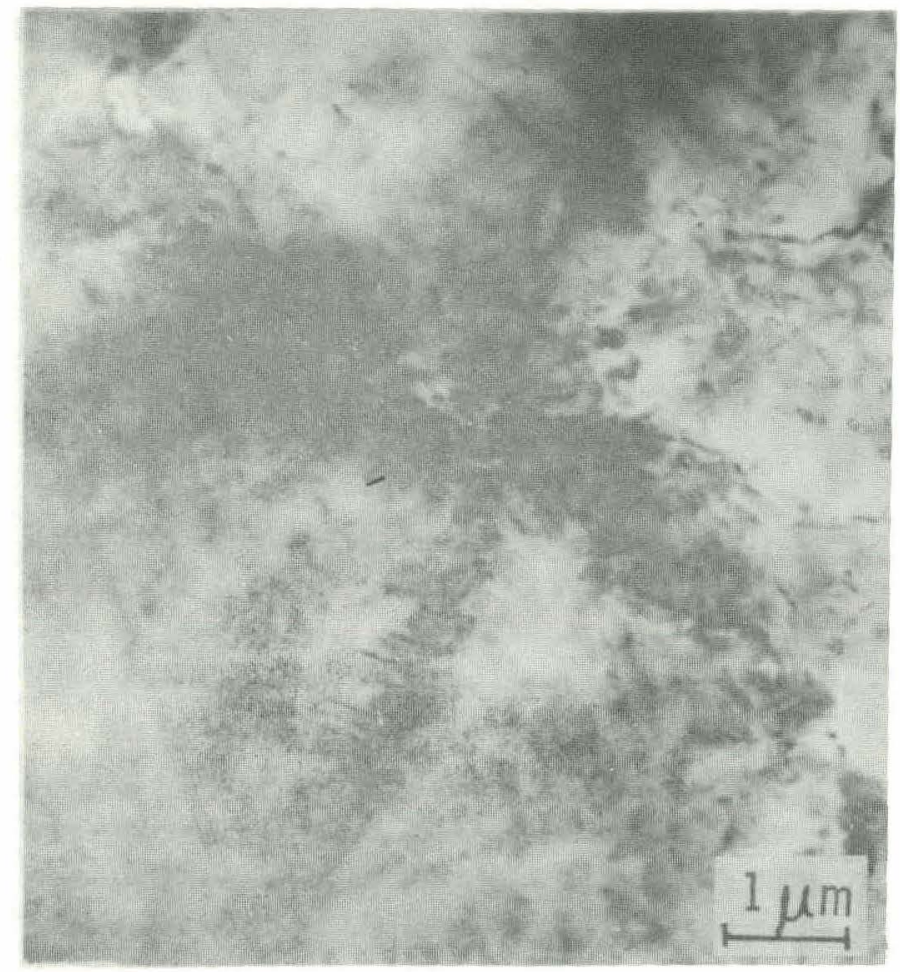

a

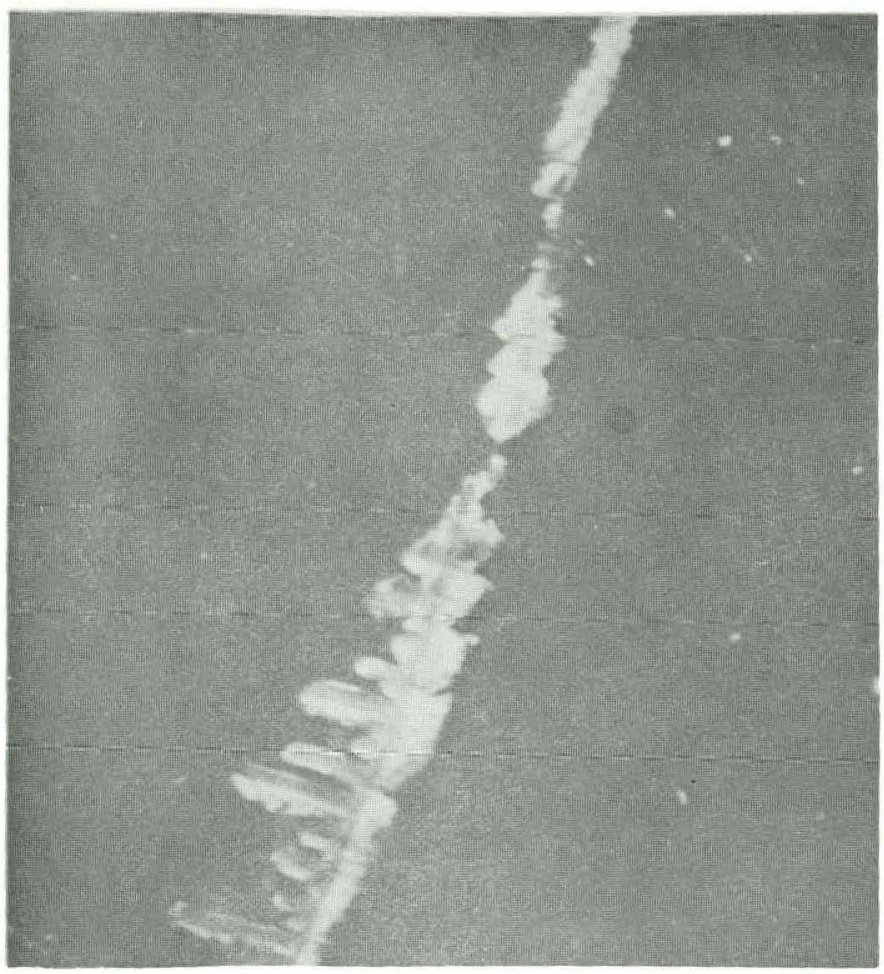

b

Fig. 4. TEM micrographs showing (a) bright-field image and (b) dark-field image of a dendrite cluster. 


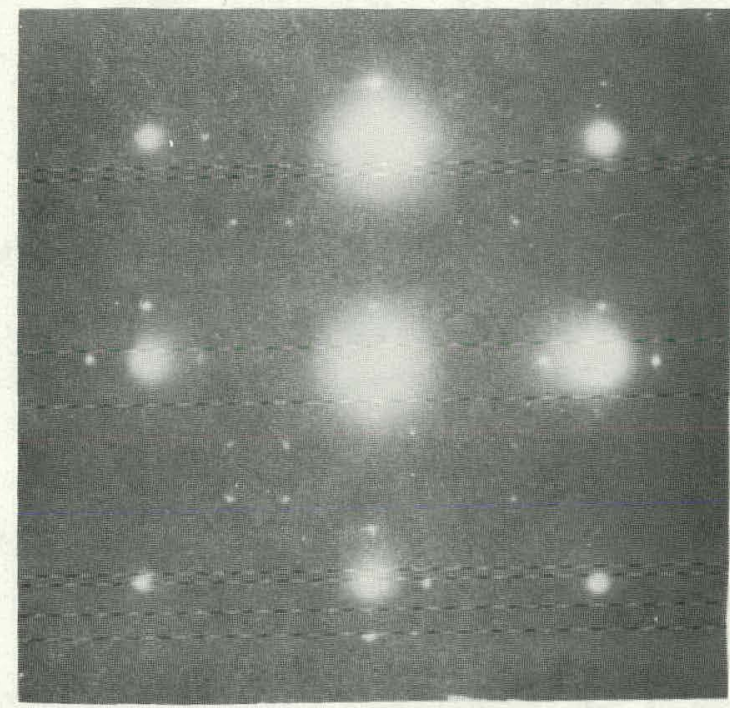

a

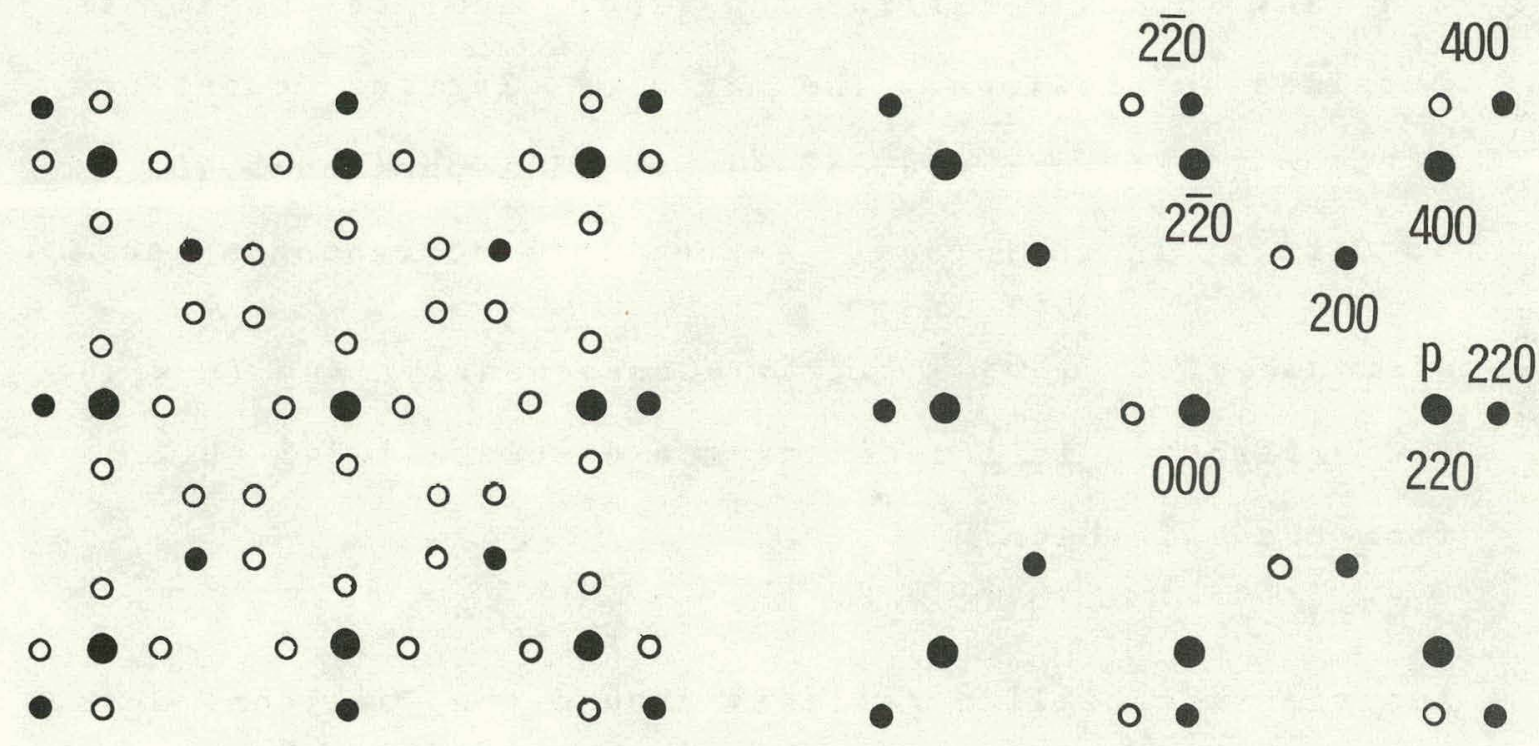

b

C

Fig. 5. (a) Selected-area electron diffraction pattern of Fig. 4, (b) schematic drawing of (a), (c) superposition of $\beta-\mathrm{SiC}$ and $\mathrm{Si}(001)$ diffraction patterns with $\mathrm{Si}(220)$ reflex $\mathrm{p}$ acting as a secondary source for double diffraction. Large and small solid dots represent $\mathrm{Si}$ and $\beta$-SiC reflections, respectively. The small solid dots represent the double-diffraction spots due to $p$. 
For analysis of the result contained in Fig. 5a the diffraction pattern of Fig. 5 b was reconstructed with the following assumptions:

1. The dendrites consist of B-Sic and grow epitaxially with [001] orientation on the [001] oriented silicon. The epitaxial relationship between SiC and silicon is perfect for the (110) B-SiC planes parallel to the (110) silicon planes. Under such conditions, extra diffraction spots due to Sic appear in the silicon pattern. The distance between the silicon main reflex and any $(h, k, 1)$ diffraction spot due to $B-S i c$ is obtained as follows. The ratio of lattice constants between $B-\operatorname{SiC}(a=4.358 \AA)$ and silicon $(a=5.403 \AA)$ 1s 0.803 . In reciprocal space, this corresponds to a distance of $1: 0.803=1.24 .5$. Consequently, any $(h, k, 1)$ S1C reflection 18 located at the distance $1.245<\mathrm{h}, \mathrm{k}, 1>$ from the main beam.

2. Additional satelite reflexes around the silicon dots are produced by the epitaxial B-SiC phase due to double reflection. Double diffraction occurs if a diffracted beam from the silicon passes into the epitaxial SiC, or vice versa. In both cases the double-diffracted beam is deterined by adding together the reciprocal lattice 


$$
\begin{aligned}
& \text { vectors corresponding to the two component } \\
& \text { diffractions. } \quad \text { Extra reciprocal lattice points } \\
& \text { displaced from the silicon matrix result. }
\end{aligned}
$$

Taking these two mechanisms into consideration and the additional fact that double diffraction from S1C (400) planes is found to be very weak, the diffraction patern of F1g. 5c was constructed. The large solid spots in this pattern are due to s111con of <001> orfentation. The small solid dots represent the SiC reflections, and the open-small dots represent the double-diffraction spots for the silicon reflex (220), p, acting as a secondary source. If this pattern 18 reproduced for the four (220) and four (400) silicon reflexes acting as secondary sources and the results are superimposed into a single schematic pattern, the superposition yields the pattern given in Fig. 5b, which describes exactly the diffraction pattern of Fig. 5 a.

Additional information on the epttaxial relationship between $B-S I C$ and $S 1$ is obtained through tilting experiments in the electron microscope. Analysis of electron diffraction patterns of [114], [112], and [1114] orlentation yields the orientation relationships summarized in Table II. 
TABLE II. Epitaxial Relationship Between B-SiC and Si

\begin{tabular}{|c|c|c|c|}
\hline \multirow[b]{2}{*}{ Orientation } & \multicolumn{3}{|c|}{ Orientation Relationship } \\
\hline & $\beta-S i C$ & para 11 e 1 & $\mathrm{Si}$ \\
\hline \multirow[t]{2}{*}{114} & {$[31 \overline{1}]$} & & 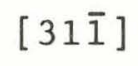 \\
\hline & {$[13 \overline{1}]$} & & {$[13 \overline{1}]$} \\
\hline \multirow[t]{2}{*}{112} & {$[3 \overline{1} \overline{1}]$} & & {$[3 \overline{1} \overline{1}]$} \\
\hline & {$[11 \overline{1}]$} & & [11̄] \\
\hline \multirow[t]{2}{*}{$\overline{1} 14$} & [3ī1] & & [3is] \\
\hline & {$[1 \overline{3} 1]$} & & {$[1 \overline{3} 1]$} \\
\hline
\end{tabular}

Further insight into the SiC growth on silicon is obtained from the following results. Figure $6 a$ shows the bright-field micrograph of a dendrite on a <112> ribbon surface. This particular surface plane is perpendicular to (111) crystal planes. This surface orientation is the result of twinning as described in the third quarterly report (2). The dendrite grows again preferentialy in <II0> directions. This 18 similar to dendrites growing on $<001>$ ribbon surfaces. Interesting is the dark-field tmage of this dendrite recorded through use of the ( $2 \overline{2} 0)$ B-SiC reflection, as indicated in Fig. 6c. The dark-field image is given in Fig. $6 \mathrm{~b}$ and shows a group of parallel layers spaced at approximately $500 \AA$ in the [1T0] direction. This result indicates that the dendrites consist of a succession of silicon and SiC layers which are stacked along (111) planes. 

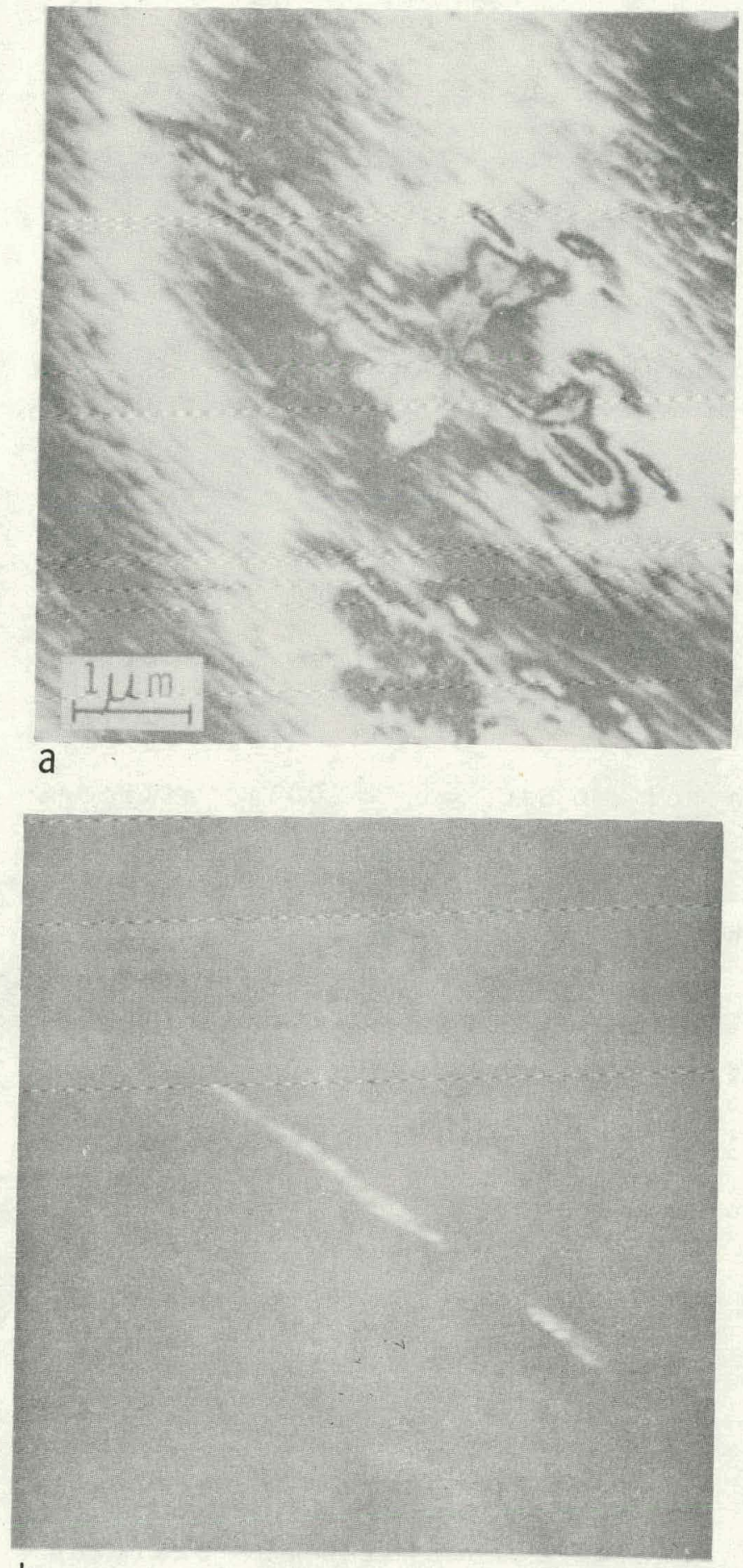

b

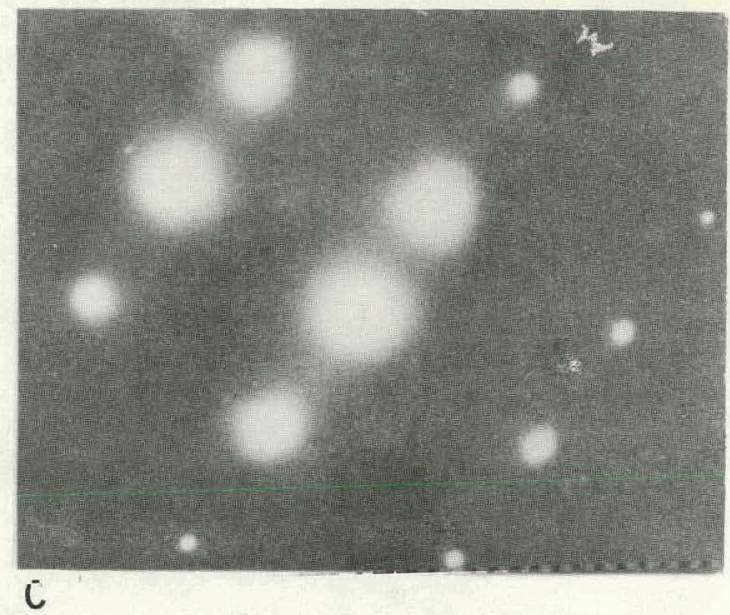

Fig. 6. TEM microgiapns showing (a) bright-field image, (b) dark-field image of a dendrite on a $<112>$ ribbon surface, and (c) electron diffraction of (a) and (b). 
The electron diffraction pattern of Fig. $6 \mathrm{c}$ indicates that the epitaxial relationship between $B-S i C$ and silicon $1 \mathrm{~s}$

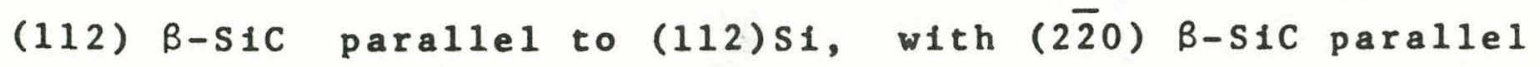

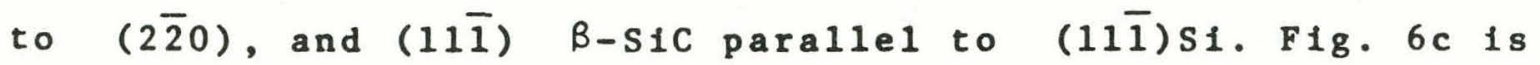
essentialiy identical with the diffraction pattern taken by tilting a [001]-oriented specimen into the [112] orientation.

The simple epitaxial relationship observed in this study is in good agreement with the results reported previously (3-5). Brown and Watts (3) and Jacobson (4) reported that the growth of B-SiC on (001) silicon substrates, by use of chemical vapor deposition, results in the orientation relationship of (001) B-S1C parallel to (001)Si with (220) B-SiC paral1el to (220)Si, and ( $2 \overline{2} 0)$

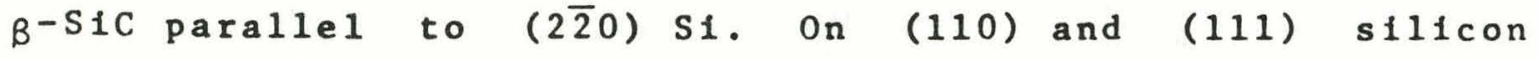
substrates, similar epitaxial relationships are established between $B-S I C$ and the silicon substrate $(3,5)$.

\section{SUMMARY}

Surface films on silicon ribbons grown by the capillary action shaping technique by use of carbon dies are analyzed through optical and transmission electron microscopy. The films are formed through vapor deposition and consist of B-SiC. The SiC shows significant structural differences, 
depending on deposition location - seed or ribbon - and on ribbon growth speed. On the seed surface the sic deposits as randomly oriented crystalites ranging in size from 700 to $1500 \AA$. close to the seed-ribbon interface the crystalite size increases to $1 \mu \mathrm{m}$. The small crystals are of well-defined crystallographic shape. With the Increasing speed of silicon ribbon growth, epitaxial formation of Sic dendrites on the silicon ribbon surface becomes the dominant SiC growth mechanism. The epitaxial growth of B-S1C occurs through preferential incorporation of (111)Sic planes parallel to (111) silicon planes according to the epteaxial relationship (001) B-SiC paraliel to (001)Si with (110) B-SIC parallel to (110)S1, and (1IO) B-SiC parallel to ( $1 \mathrm{IO}) \mathrm{S} 1$.

6. REFERENCES

1. Quarterly Technical Progress Report Number 1 , JPL Contract 954144, G. H. Schwuttke, Principal Investigator, August 1975 .

2. Quarterly Technical Progreas Report Number 3, JPL Contract $954144, \quad$ G. H. Schwuttke, Princ1pal Investigator, March 15, 1976.

3. A. S. Brown and B. E. Watts, J. App1. Crysta1logr. 3, 1972 (1970).

4. K. A. Jacobson, J. Electrochem. Soc., 118,1001 (1971).

5. I. H. Khan, Mater. Res. Bul1. 4, S285, Pergamon Pres8, Inc. (1969). 
CURRENT OUTLOOK FOR LARGE-AREA SILICON SHEET -
A TECHNOLOGY PROJECTION
by

A. Kran

1. INTRODUCTION

Interactive computer simulation is used to support the development of technological and economic data required to define the potential of silicon-sheet growth for large-scale photovoltaic applications. The silicon-ribbon growth production-unit model simulates the complex interactions between physical variables pertaining to ribbon processing and the economic parameters associated with product manufacturing and business management.

As described in the second quarterly report (1), the production-unit concept, together with technology forecasting and sensitivity analysis, was used to compare single- and multiple-ribbon growth systems for their ability to provide low-cost slifon-sheet materlal. Conclusions favored single-ribbon growth and suggested that processing-technology improvements, offered the best potential for achieving low-cost silicon-sheet material objectives within the shortest perlod of time. This report 
extends that work to include an assessment of energy-capacity cost at the sheet material level, using system simulation and probability concepts (2). It also associates technology parameters projected in time with an estimated probability of the event's occurring at a specific point. This results in a cost ( $\$ / k W E)$ versus time relationship and in an ability to compare our projections of future sheet material cost with ERDA projections for solar-array costs.

Since single-ribbon growth, on the basis of previous work, appeared to have more potential for achieving low-cost material objectives, no further analysis of multi-ribbon growth is, planned without additional data.

2. TECHNOLOGY FORECASTING METHODOLOGY

\subsection{General}

Technology forecasting, today, is recognized as an integral part of the decision-making process, leading to a commitment of resources to future products. Properly structured and applied, it is a useful tool for looking ahead to increasingly complex technology and to an environment marked by rapid changes. Technology forecasting is also a 
structure for communication, requiring the forecaster to define his terms and open to challenge his technical expertise, data, thought process, and blases. It compels him to make his assumptions explicit, which does not guarantee the correctines of forecast, but does offer the opportunity to confirm assumptions and to ensure that the data used are the best avallable.

Many forecasting techniques are reported in the iiterature. Most concern themselves with the evolution of a product, such as a computing system, calculator, or automobile, and involve the fitting of some mathematical function or curve to historical data. The forecast is obtained by projecting the fitted curve into the future. Learning-curve analysis is an example of this type of general, aggregate projection, which is useful for reviewing the general viability of a product or technology. Once a project is under way, however, more specific monitoring and projection techniques must be added, so that progress from a "bottoms-up" point of view. can be compared with management-stated "tops-down" program objectives. 


\subsection{Forecasting Technique}

Our procedure for forecasting silicon-sheet manufacturing technology is predicated upon the production-unit concept:

1. Define a specific production unit.

2. Profect technology capability of parameters.

3. Introduce chronology.

4. Evaluate numerically to obtain cost vs time.

The production-unit approach reduces the complexity of interaction among processing sectors in a manufacturing operation, and may be thought of in terms of three elements: processing technology, resources, and raw materials. Its purpose is to transform polycrystalline bulk silicon into sheets of single-crystal or controlled-crystallography material suitable for solar-cell fabrication. These three elements are described to the system as a specific combination of manpower, crystal-growing equipment, and polycrystalline silicon needed to progress through the crystal-pulling sector in a solar-cell manufacturing operation. 
The "baseline" production unit, or starting point for the projection, is developed from speciflc data which reflect processing technology practiced in the laboratory and assumed transferable to a production environment, and from estimated direct- and indirect-cost ltems, plus profit, representative of a small- to medium-size concern. From this baseline, any one of the 27 model parameters can be projected in terms of what is anticipated in the "near-future" (soon), what is expected in the "future," and what will be approached as the "limtt." This is done without commitment to a specific time frame. Subsequently, in order to introduce chronology, these technology projections are associated with a probability of meeting particular technology objectives by a speciftc point in time. For example (as further discussed In section 2.4), we estimate for 1985, with a probab111ty of $70 \%$, that ribbons between 10 and $25 \mathrm{~cm}$ wide will be routinely pulled. After numerical evaluation of the cumulative probability distribution function, calculation, of energy cost at the level of silicon-sheet material, and statistical analysis of these cost figures, a cost-versus-time curve is plotted.

This forecasting technique requires two projections: the first, relating to technology and 1 ts limita, hould be 
provided by the technologtst; the second, pertaining to the probability of implementing stated technology objectives, is more management-oriented, as implementation schedules depend upon allocation of resources to develop the technology. Finally, because this technique is readily applied and rapidly iterated, it lends 1 tself well as a tool to be used jointly by technology developers and planners interested in tracking development progress and cost profiles.

\subsection{Baseline Definition}

The baseline production unit may be thought of as a reference point from which all projections are made. The list of 27 input parameters to the model is shown in Fig. 1 and is divided into three categories. The ribbon data category contains processing-related parameters, such as ribbon width $(2.5 \mathrm{~cm})$, growth rate $(1.5 \mathrm{~m} / \mathrm{hr})$, and thickness $(0.3 \mathrm{~mm})$. Wherever possible, such as in the case of ribbon width, growth rate, or thickness, state-of-the-art values are used.

The direct-cost category comprises the crystal-growth system cost - which, at $\$ 50,000$, is essentially the cost of a Czochralski puller modified for ribbon growth - equipment 1 ife ( 7 years), and 1 nterest rate $\cdot(10 \%)$, so that equipment 


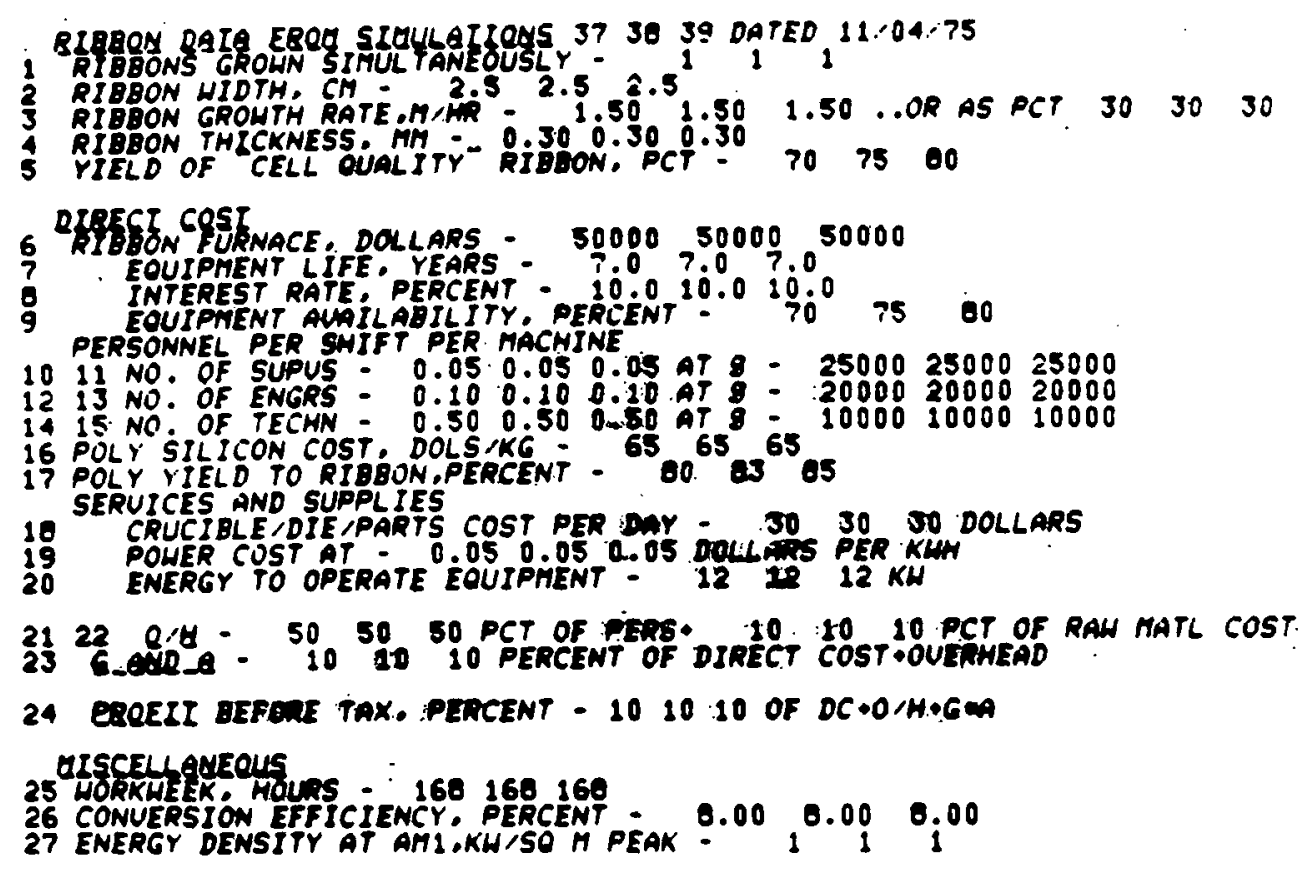

Fig. 1. Baseline input parameters to production unit.

capital recovery can be calculated. Equipment availability is defined as the percent of time the system ls avallable for crystal pulling, excluding setup, polysilicon melt-down, and random machine fallure time. Also included here are the direct personnel required to assure efflcient operation of the system, polysilicon cost, and services and supplies, which include die cost. Overhead, general and administrative expenses, and profit are defined as percentages relating to other direct-cost 1tems.

The third category defines the workweek in terms of hours and of energy-conversion effictency at AMl, a hypothetical value to assess energy-capacity cost at the level of s111con-sheet material. 
Since ribbon growth is still considered to be in the development, not manufacturing, phase, parameters such as yield of "cell quality" (sultable for solar-cell fabrication) ribbon, poly yield to ribbon, and machine availability are estimated $1 \mathrm{n}$ terms of what could be expected in a production environment on the basis of laboratory experience. Since these values are subject to interpretation, three cases are shown, reflecting an outlook ranging from conservative to optimistic.

Output from the model, shown in Table I, consists of the major factors contributing to sheet material and energy-capacity cost. For our purposes, the most conservative values (energy-capacity cost: $\$ 8476 / k W E$ peak) are used as the baseline. They include the average yielded growth rate $\left(0.02 \mathrm{~m}^{2} / \mathrm{hr}\right)$, the yield factor $(0.56)$, plus the following direct-cost elements, calculated in dollars/m²: equipment capital recovery, personnel, polysilicon, and services and supplies. Also calculated in dollars/m $\mathrm{m}^{2}$ are overhead cost, G\&A expense, and profit. The addition of these items results in a total dollars/m figure. for silicon-sheet material $(\$ 678)$, representing a seling price to a manufacturer, or purchase coot to a buyer. 
TABLE I. Economics of Silicon Ribbon (Baseline) One Ribbon Puller

\begin{tabular}{|c|c|c|c|}
\hline IRULAIIQA DI ANR NO.1 11.04 & 37 & 38 & 39 \\
\hline RIBBONS GROWN SIMUL TANEOUSLY & 1.00 & 1.00 & 1.00 \\
\hline RIBBON WIDTH, CM & 2.50 & 2.50 & 2.50 \\
\hline AUG YIELDED GRONTH RTE.SO MIHR & 0.02 & 0.02 & 0.02 \\
\hline COMBINED YIELD FACTOR & 0.56 & 0.62 & 0.68 \\
\hline $\begin{array}{l}\text { DIRECT COST IN DOLSISO METER } \\
\text { EQUIPMENT CAPITAL RECOL'ERY } \\
\text { PERSONNEL } \\
\text { POLY SILICON COST } \\
\text { SERUICES SSUPPLIES }\end{array}$ & $\begin{array}{r}66.54 \\
224.49 \\
81.13 \\
71.45\end{array}$ & $\begin{array}{r}57.96 \\
195.56 \\
72.99 \\
63.66\end{array}$ & $\begin{array}{r}50.94 \\
171.89 \\
66.82 \\
57.20\end{array}$ \\
\hline SUBTOTAL: & 443.61 & 390.17 & 346.84 \\
\hline $\begin{array}{l}\text { OUERHEAD COST IN DULS.SO METER } \\
\text { GQA EXPENSES IN DULS.SO METER } \\
\text { PROFIT IN DOLLARS.SO METER }\end{array}$ & $\begin{array}{r}116.79 \\
56.04 \\
61.64\end{array}$ & $\begin{array}{r}102.32 \\
49.25 \\
54.17\end{array}$ & $\begin{array}{l}90.48 \\
43.73 \\
40.12\end{array}$ \\
\hline TOTAL COST IN DOLSISO METER & 670.08 & 595.91 & 529.16 \\
\hline DOLLARS PER & 8476.03 & 7448.89 & 6614.44 \\
\hline
\end{tabular}

2.4 Parameter Projection and Numerical Evaluation

All technology projections are made from the baseline and address three future points in time: near-future, future, and $11 \mathrm{mit}$. These points define the expected capabilities of the particular technology, silicon-sheet growth in this case, from lts state-of-the-art to full maturity. Chronology is introduced by estimating the probability of meeting the objective associated with the technology parameter at a stated point in time.

Ribbon-width capability is used to lilustrate this technique. As can be seen from Table II, we project for 1980, with a probability of only 0.05, that rlbbons between $2.5 \mathrm{~cm}$ wide, our current baseline; and $5 \mathrm{~cm}$ wide will be 
TAIBLE II. Ribbon-Width Capability

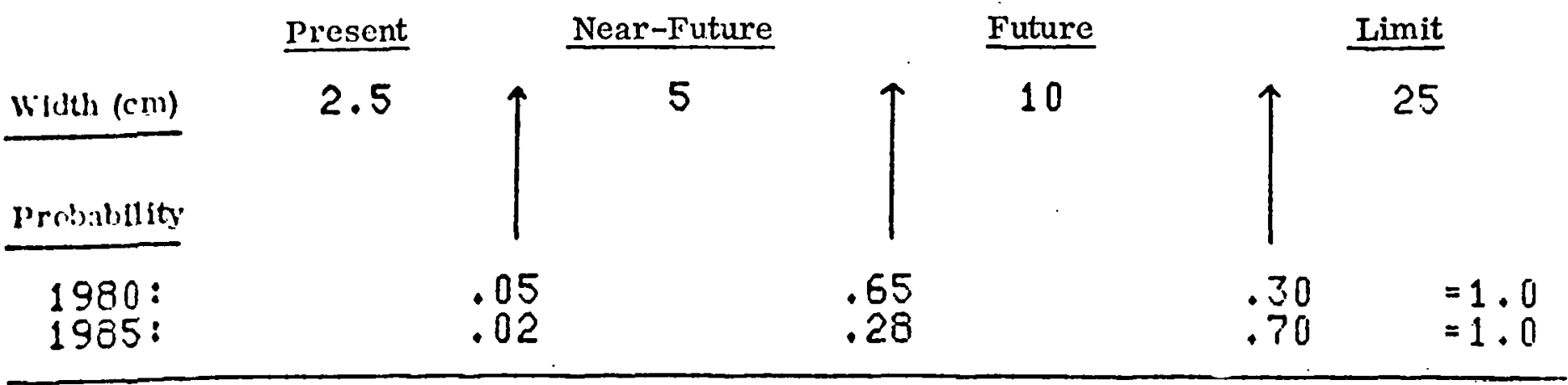

routinely pulled. In other words, we are convinced that chis capability will be achieved. We estimate the same probsility to be 0.65 that ribbon width will be between 5 and $10 \mathrm{~cm}$, and 0.30 that ribbon width w111 be between 10 and $25 \mathrm{~cm}$. The probabilities are mutually exclusive and add up to 1. For 1985, the probabilities are $0.02,0.28$, and 0.70 , respectively. A graphical representation of the foregoing 1s shown in Figs: 2 and 3 .

The probability is continuous and even for each point between the threc intervals, as is seen from the 1980 cumulative distribution function shown in Fig. 4, where we transform a uniformly distributed sequence of random numbers $(y-a x 1 s)$ Into one that is non-uniformly distributed and that 18 based upon our estimated probability distribution (x-axis). This cumulative probability distribution function 18 then evaluated numerically, as seen 1 n Figs. 5 and 6 . For example, using the same random number (0.55), P1g. 5. (1980) yields a 9-cm-wide ribbon, whereas F1g. 6 (1985) ylelds a 15.5-cm-wide ribbon. 


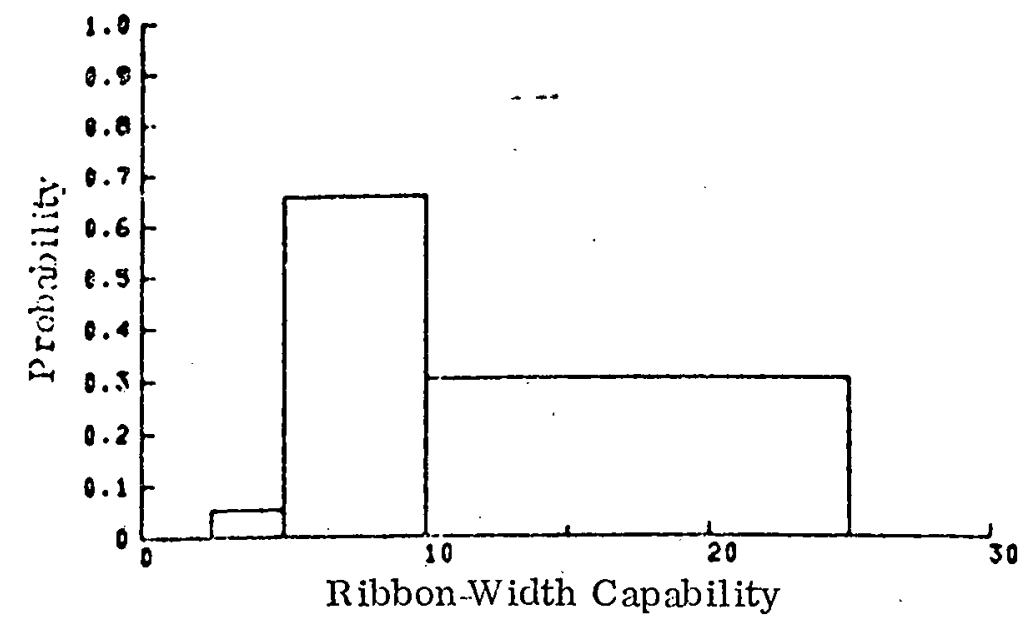

Fig. 2. Ribbon-width capability vs $\mathbf{1 9 8 0}$ probability.

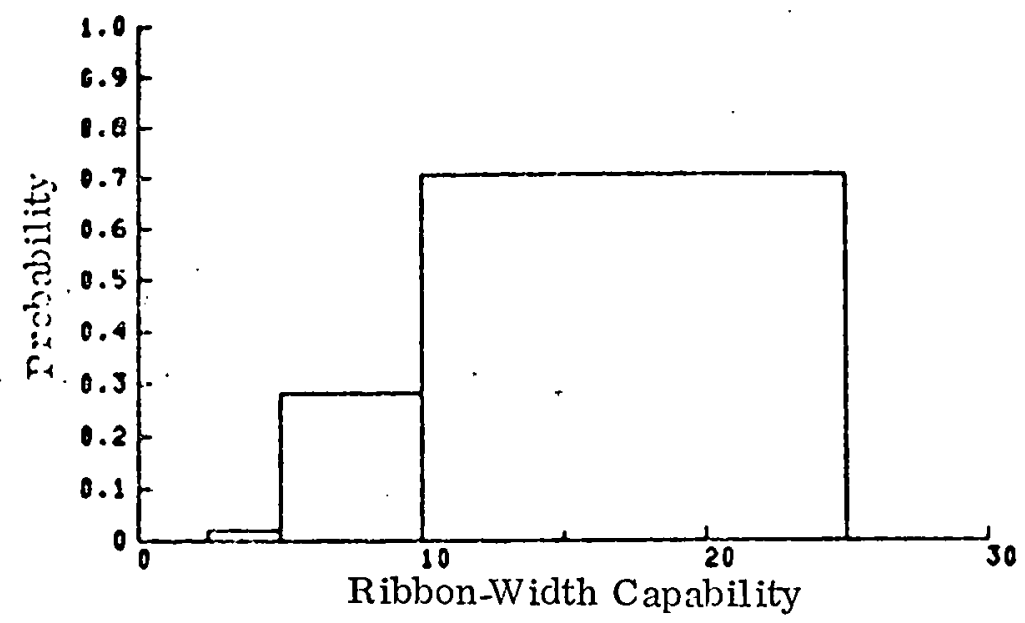

Fig. 3. Ribbon-width capability vs 1985 probability.

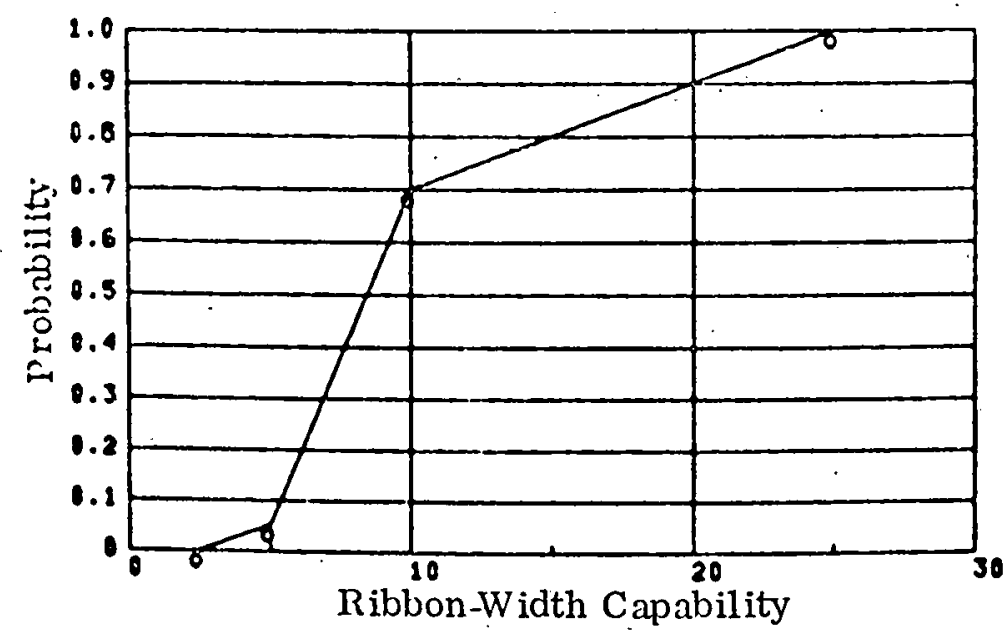

Fig. 4. Ribbon-width capability vs 1980 cumulative probability. 


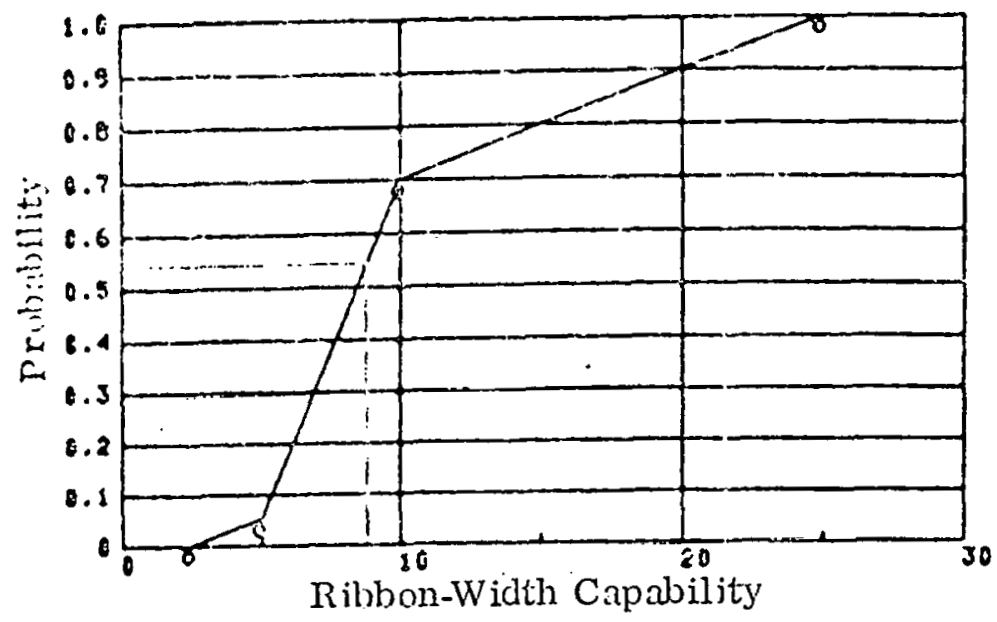

Fig. 5. Ribbon-width capability vs 1980 cumulative probability-example of numerical evaluation technique.

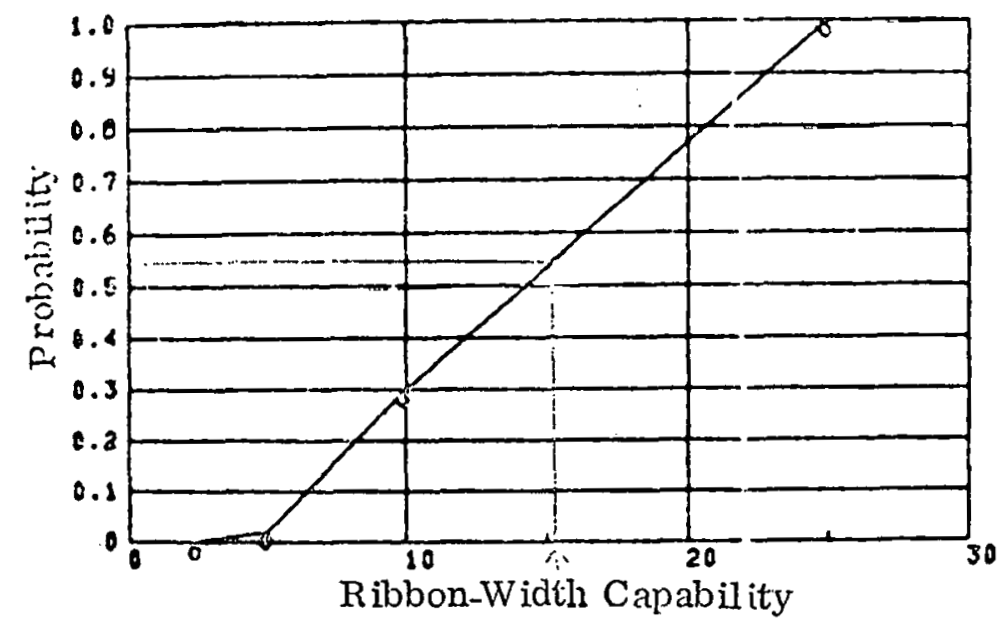

Fig. 6. Ribbon-width capability vs 1985 cum slative probability-example of numerical evaluation tech:ique.

3. COMPUTER PROGRAM FOR TECHNULOGY FORECASTING

\subsection{Data Flow Model}

The computer program is written in APL, a high-level programming language, and provides an interactive system for technology projection. Its operation is briefly described In confunction with the data fluw model shown in Fig. 7 . 


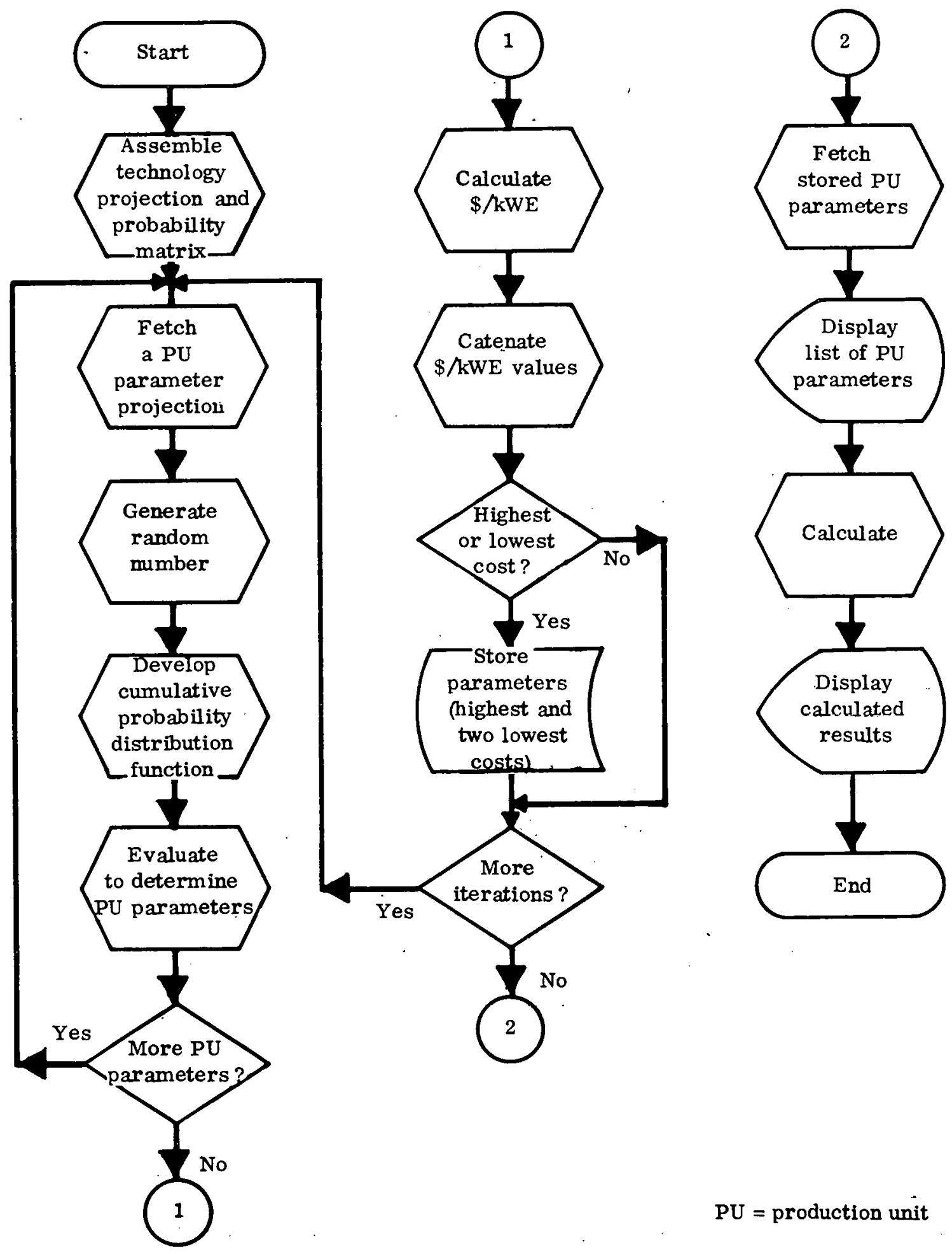

Fig. 7. Technology-forecasting data flow model. 
The program operates on a 27-by-8 matrix, containing 4 columns of production-unit values and 3 columns of estimated probabilities pertaining to them (see section 4.2). As deplcted in Fig. T, the program fetches the first row of the matrix, generates a random number, develops the appropriate cumulative distribution function from the given probabilities, and then numerically evaluates the cumulative distribution function, using a random number generator, to determine the specific production-unit parameter. It then proceeds to the next row until a complete set (27) has been developed. Subsequently, energy-capacity costs (three) at the sflicon-sheet material level are calculated (Fig. 1) and storeä, as are three sets of input parameters (those resulting in the highest and two lowest $\$ / k W E$ figuces). This operation is terated the number of times speclfied (600 cost figures each for 1980 and 1985). Finally, a statistical analysis provides the data points for the ivurve (shown in section 4.5 ).

\subsection{Listing of Functions}

Following is a display of functions needed to operate the program In conjunction with the code published in Ref. 1 . The computer code is documented to facllitate understanding and maintenance by others. 


\section{DESCRIBE}

THESE FUNCTIONS IN CONSUNCTION HITH THE PRODUCTION UNIT MOEL CONSTITUTE AN INTERACTIUE SYSTEM FOR TECHNOLOGY PROJECTION OF ENERGY CAPACITY COST AT THE LEUEL OF SILICON SHEET MATERTAL (DOLSIKHE).

THE SYSTEM CONTAINS THREE USER ACCESSED FUNCTIONS COEFINE TMOIFY PS. AND PHICH MAY BE CHANGED BY SEIS UP THE PROJECT OPERATES UN ER. CALCULATING ENERGY CAPACITY COST AND KEEPING THREE SETS OF. INPUT WARIABLES -THOSE RESULTING IN TNE MIGHEST AND TWO LOWEST ENERGY CAPACITY COSTS. ABOUT 2500 PROJECTIONS CAN BE CALCULATED. BEFORE THE WORKSPACE IS FULL.
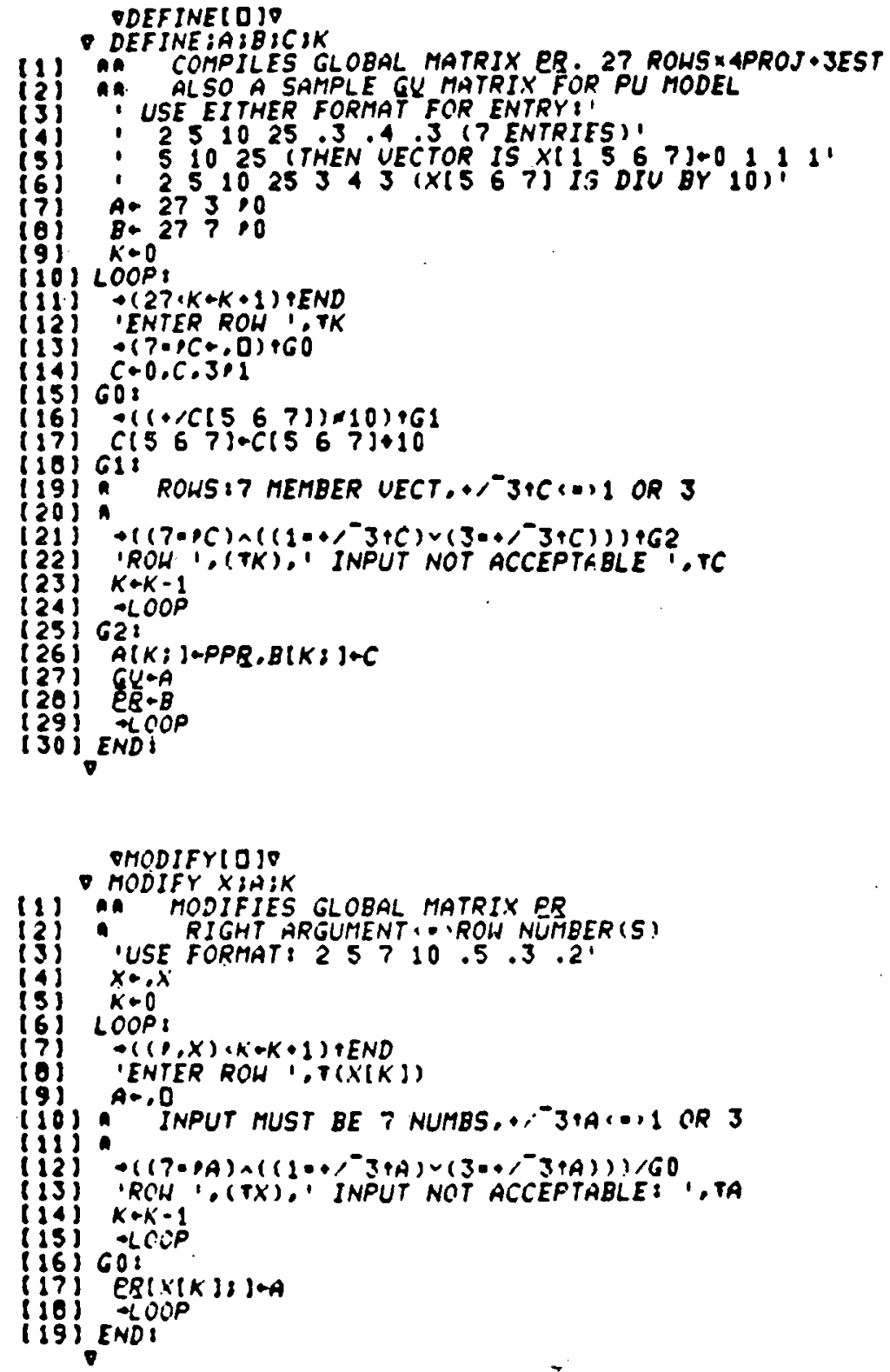


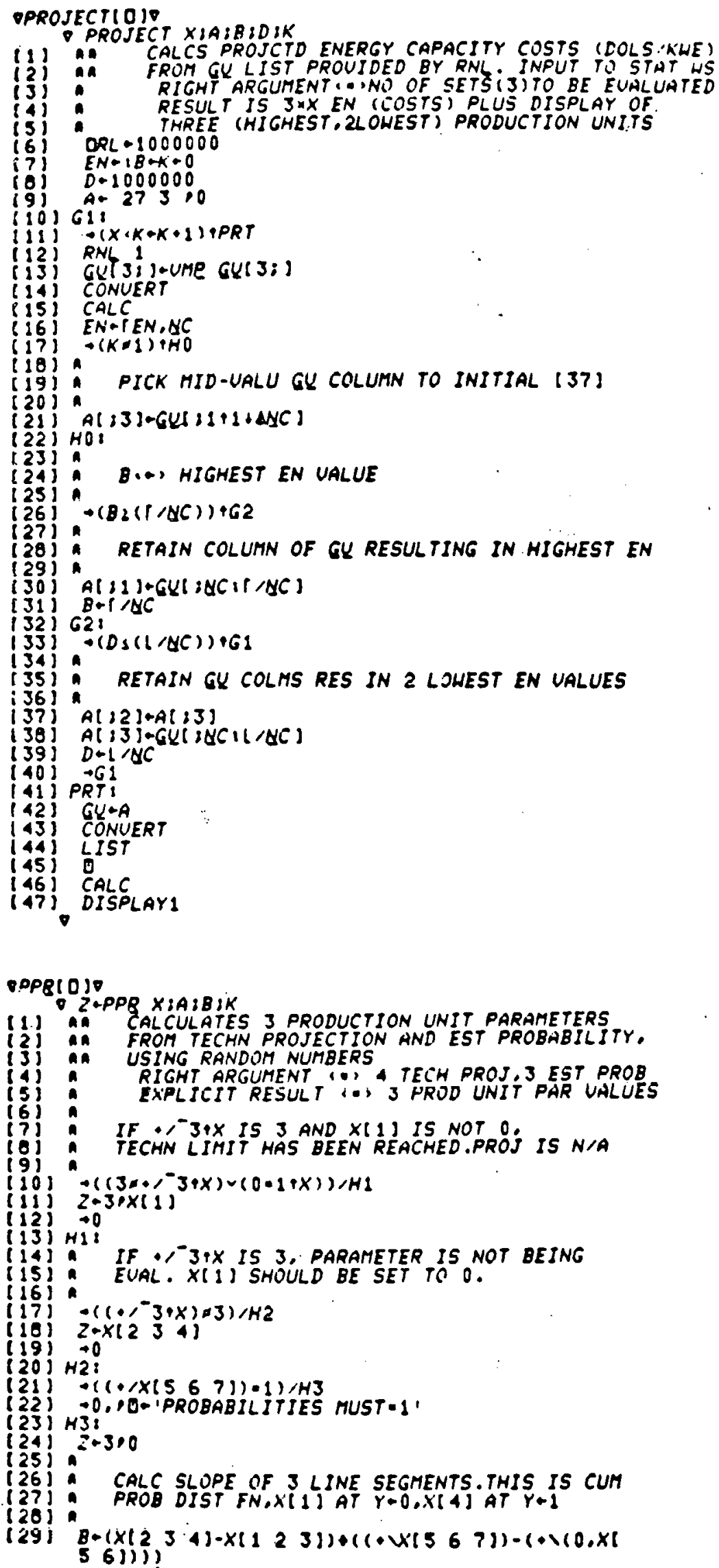


(30) $K+0,15$

(32)

EUAL CUM PROB DIST FN (3 (IALUES)

(33)

(34) $+(3, k-K+1)<0$

(35) A-RAY

(36)

(37)

39 ;

(40) a

IS RANDOI NO IN IST LINE SEG RANGE?

$\rightarrow(A, \times(5)) / G 1$

(41)

(43) $Z(K)+X(1)+(B(1) \times A)$

(44) $1600 P$

(45) $61:$

(46): IS RAN NO IN 2ND LINE SEG RANGE?

(40).

(49) $\rightarrow(A)+/ X(5.6)) / G 2$

(50) $Z(K)+(X 12)) \cdot(B[2] \times(A-X(5)))$

(51) -LOOP

$152\} 628$

(53) A. IF RAN NO AN 1.IT MUST BE IN 3RD SEG

(54)

(55) $+(A \times 1) / 63$

(56) $\geq(K)+x(4)$

(57) 2000

(50) $63:$

(59) $2(k)+(X) 3))+(B(3) \cdot(A-\ldots)(56))$

(60) - 6000

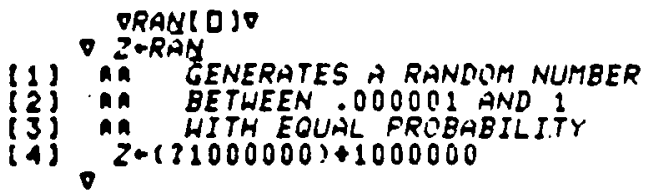

DRNL 1090

(1) RN COMPILES PROD UNIT INPUT PAR UALUES GU

(2) AN FROM GLOBAL MATRIX ER

(3) N RIGHT ARGUMENT : NUMBER OF SETS

(4) ONE SET IS REOD AS INPUT TO FN CALC

(6) $D$ IS $x$ BY 3 MATRIX TO INDEX GU

(8) $D+(x, 3) \cdots(x \times 3)$

(9) $G U+(27,3 \times x) 10$

(10) $A-273 \circ 0$

(11) $B+P B$

(12) $K 1=K+0$

(13) $L O O P$

(14) A COMPILES A GU SET

(15)

(16) $+(27 \cdot K \cdot K \cdot 1)+60$

(17) $A(K))+P P B \quad B(K)]$

(18) $\rightarrow L 00 P$

(19) 60 :

(20.)

(21)

(22)

(23) 6

(24) k-1

(25) $L O O P$

(26) END:

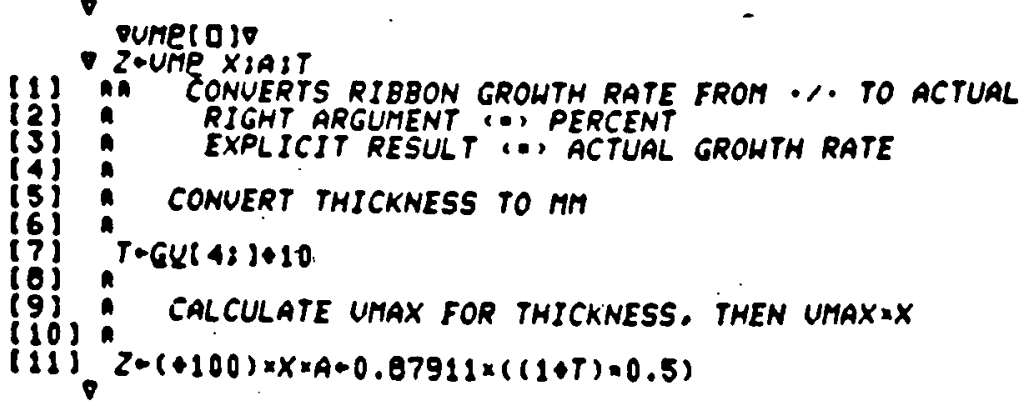




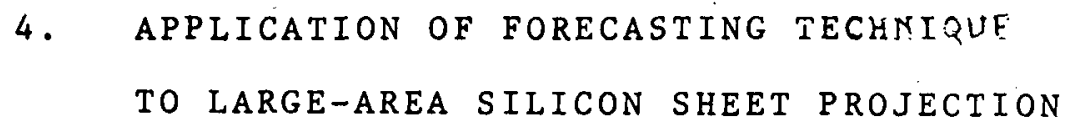

4.1 Profection of Silicon Sheet Technology Parameters

The last quarterly report (3) concluded that single-ribbon growth and processing-technology improvement offered the best potential for achieving low-cost sheet-material objectives. Consequently, only technology-sensitive parameters ( 13 out of 27 ) are projected for this analysis, as shown in Table III. The first column contains the baseline, and the remaining three our projections.

TABLE III. Silicon Ribbon Technology Projection

\begin{tabular}{|c|c|c|c|c|c|}
\hline $\begin{array}{l}\text { Item } \\
\text { No. } \\
\end{array}$ & Parameter & Present & $\begin{array}{l}\text { Near- } \\
\text { Future }\end{array}$ & Future & $\underline{\text { Limit }}$ \\
\hline 2 & Ribbon width (cm) & 2.5 & 5 & 10 & 25 \\
\hline 3 & Ribbon growth rate $\left(\%\right.$ of $\left.V_{\max }\right)$ & 30 & 40 & 50 & 60 \\
\hline 4 & Ribbon thickness (mm) & 0.30 & 0.20 & 0.15 & 0.10 \\
\hline 5 & Yield of "cell grade" ribbon (\%) & 70 & 80 & 90 & 95 \\
\hline 6 & Ribbon furnace cost $\left(\$ \times 10^{3}\right)$ & 50 & 25 & 20 & 15 \\
\hline 7 & Equipment life (years) & 7 & 8 & 10 & 12 \\
\hline 9 & Equipment availability (\%) & 70 & 80 & 90 & 95 \\
\hline 14 & Number of technicians & 0.50 & 0.25 & 0.15 & 0.10 \\
\hline 16 & Polysilicon cost $(\$ / \mathrm{kg})$ & 65 & 45 & 30 & 6 \\
\hline 17 & Poly yield to ribbon (\%) & 80 & 85 & 90 & 95 \\
\hline 18 & Services and supplies (\$/day) & 30 & 25 & 20 & 10 \\
\hline 20 & Energy to operate equipment (kWE) & 12 & 11 & 10 & 3 \\
\hline 26 & Cell conversion efficiency $(\%)$ & 8 & 10 & 12 & 15 \\
\hline
\end{tabular}


Using the three projections as input to our production-unit model results in Table IV, where simulation numbers 43,44 , and 45 represent the "near-future," "future," and "limit" projections. Accordingly, we conclude at this point that silicon-sheet growth, as a technology, has the capability of providing the material at the required cost to meet a $\$ 500 / k W E$ array-cost objective at a later point in time than represented by simulation number $44(\$ 314 / \mathrm{kWE})$, but well before the technology limit is reached (simulation number 45, $\$ 42 / \mathrm{kWE}$ ). Th1s projection 1s plotted in F1g. 8 (lower curve), together with another one, Independently arrived at. As can be seen, the difjerence between the two is Insignificant.

TABLE IV. Near-Future, Future, and Limit Projection of Silicon Ribbon Technology

\begin{tabular}{|c|c|c|c|}
\hline SLOULAILOA RI ANE UQ.: 11104 & 43 & 44 & 45 \\
\hline RIBBONS GROUN SIMULTANEOUSLY & 1.00 & 1.00 & 1.00 \\
\hline RIBBON HIDTH. CH & 5.00 & 10.00 & 25.00 \\
\hline AUC YIELDED GROUTH RTE.SO HIMR & 0.08 & 0.29 & 1.19 \\
\hline COMBINED YIELD FACTOR & 0.68 & 0.01 & 0.90 \\
\hline $\begin{array}{l}\text { DIRECT COST IN DOLS ISO METER } \\
\text { EOUIPMENT CAPITAL RECOUERY } \\
\text { PERSONNEL CON COST } \\
\text { POLY SILICON COST } \\
\text { SERUICES'SUPPLIES }\end{array}$ & $\begin{array}{l}7.01 \\
36.13 \\
30.84 \\
14.80\end{array}$ & $\begin{array}{r}1.33 \\
8.17 \\
12.94 \\
3.60\end{array}$ & $\begin{array}{l}0.22 \\
1.79 \\
1.55 \\
0.61\end{array}$ \\
\hline SUBTOTAL: & 88.86 & 26.04 & 4.16 \\
\hline $\begin{array}{l}\text { OUERMEAD COST IN DOLS SO METER } \\
\text { GAAEXPENSES IN DOLS SSO METER } \\
\text { PROFIT IN DOLLARSISO METER }\end{array}$ & $\begin{array}{l}20.16 \\
10.900 \\
1.1 .99\end{array}$ & $\begin{array}{l}5.13 \\
3.12 \\
3.43\end{array}$ & $\begin{array}{l}1.03 \\
0.52 \\
0.57\end{array}$ \\
\hline TOTAL COST IN DOLS/SO METER & 131.92 & 37.72 & 6.29 \\
\hline DOLLARS PER & 1319.22 & 314.36 & 41.92 \\
\hline
\end{tabular}




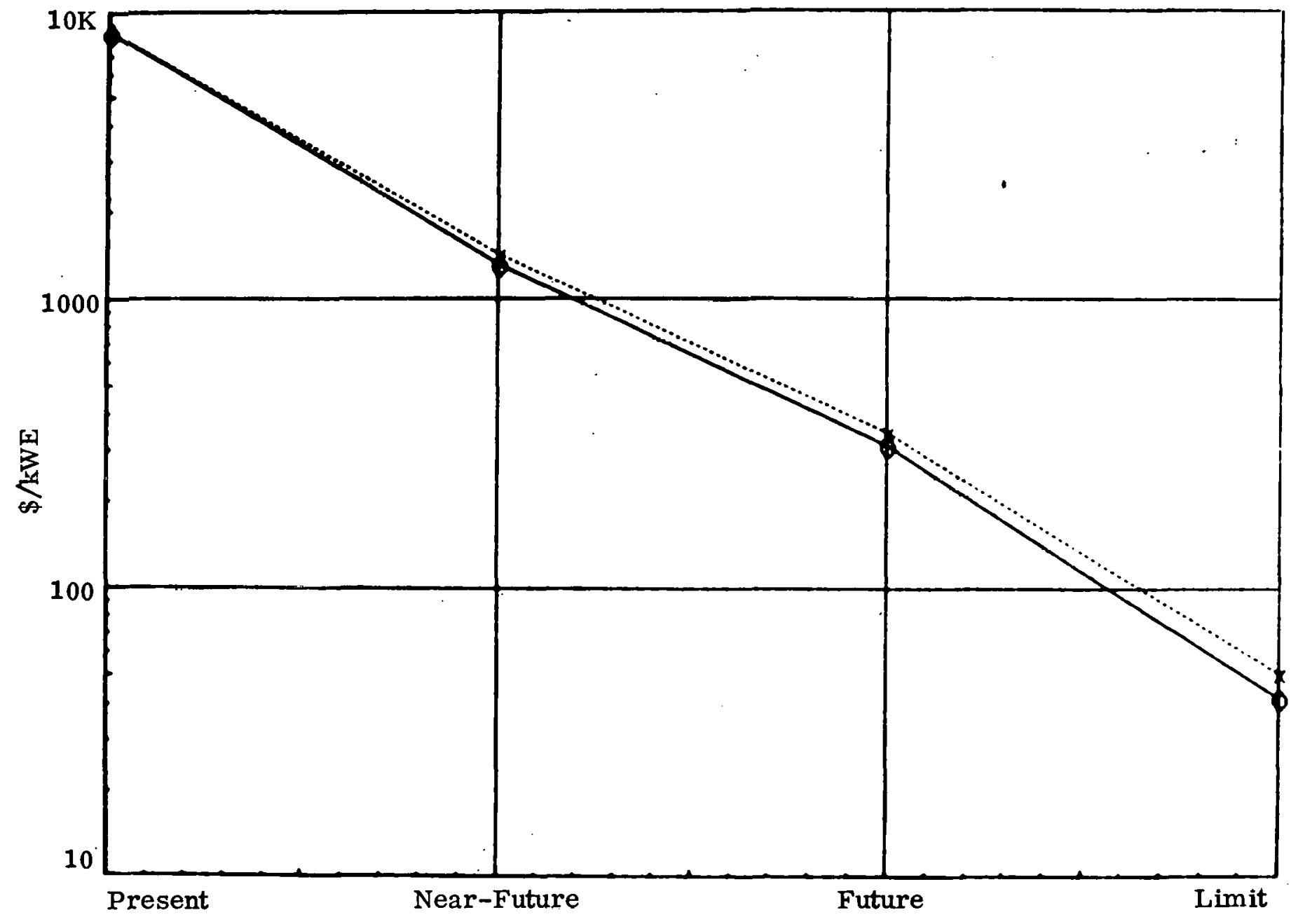

Fig. 8. Silicon ribbon technology projection.

4.2 Association Between Technology Capability and Time

As described in section 2.4, each technology parameter, in order to introduce chronology, is coupled to a point in time by means of an estimated probability that the projection w111, In fact, materialize. Subsequently, the cumulative probäbilty distribution function is evaluated numerically sy computer, using a random number generator. The computer 
program operates on a predefined 27-row by 8-column matrix. Although similar matrices could be developed for each year, only two were defined for this study $(1980,1985)$, shown as Tables $V$ and VI. The first column of each matrix corresponds to the production-unit parameter item number (see Fig. 1). The next column represents the baseline, the following three are the projections, and the remaining three the estimated probabilities. Only the latter are changed to simulate the progression of time. For Instance, the second row refers to ribbon width, with values previously shown in Table II. Whenever probabilities are listed as 1 , the corresponding production-unit parameter is not subject to this probabilistic evaluation.

4.3 Approach to Parameter Projection

Application of this technique requires a technical understanding of what the technology 1 s capable of achieving, an assessment of state-of-the-art, and, finally, judgment wịth respect to the timing of subsequent implementation. If silfcon-sheet technology is to become cost-effective for photovoltalc applications, then improvement of width capability is of prime importance. During the last few years, ribbon width has increased from 1 to $2.5 \mathrm{~cm}$, with $5 \mathrm{~cm}$ expected in the near-future. This factor-of-5 improvement is one reason for profecting $25 \mathrm{~cm}$ 
TABLE V. 1980 Technology Projection and Estimated Probability Matrix

\begin{tabular}{|c|c|c|c|c|c|c|c|}
\hline \multirow[b]{2}{*}{$\begin{array}{l}\text { Item } \\
\text { No. } \\
1 \\
2 \\
3 \\
4 \\
5 \\
6 \\
7 \\
0 \\
9 \\
10 \\
11 \\
12 \\
13 \\
14 \\
15 \\
16 \\
17 \\
18 \\
19 \\
20 \\
21 \\
22 \\
23 \\
24 \\
25 \\
26 \\
27\end{array}$} & \multirow[b]{2}{*}{ 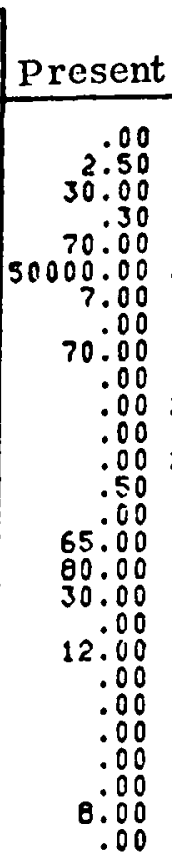 } & \multirow[b]{2}{*}{$\begin{array}{r}\text { Near- } \\
\text { Future } \\
2.00 \\
5.00 \\
40.00 \\
.00 \\
80.00 \\
25000.00 \\
8.00 \\
10.00 \\
80.00 \\
25000.05 \\
20000.000 \\
.000 \\
10000.050 \\
45.00 \\
85.00 \\
25.00 \\
1.05 \\
11.00 \\
50.00 \\
10.00 \\
10.00 \\
10.00 \\
160.00 \\
10.00 \\
1.00\end{array}$} & \multirow[b]{2}{*}{$\begin{array}{r}\text { Future } \\
1.00 \\
10.00 \\
50.00 \\
90.15 \\
90.00 \\
20000.00 \\
10.00 \\
10.00 \\
90.00 \\
.05 \\
25000.00 \\
20000.100 \\
10000.00 \\
30.00 \\
90.00 \\
20.00 \\
10.05 \\
10.00 \\
50.00 \\
10.00 \\
10.00 \\
10.00 \\
168.00 \\
12.00 \\
1.100\end{array}$} & \multirow[b]{2}{*}{$\begin{array}{r}\text { Limit } \\
15.00 \\
25.00 \\
60.00 \\
95.10 \\
95.00 \\
15000.00 \\
12.00 \\
10.00 \\
95.00 \\
25000.00 \\
20000.10 \\
10000.00 \\
5.00 \\
95.00 \\
10.00 \\
0.05 \\
9.00 \\
50.00 \\
10.00 \\
10.00 \\
10.00 \\
168.00 \\
15.00 \\
1.00\end{array}$} & \multicolumn{3}{|c|}{ Probability } \\
\hline & & & & & $\begin{array}{r}1.00 \\
.05 \\
.20 \\
.25 \\
040 \\
.60 \\
.10 \\
1.00 \\
.40 \\
1.00 \\
1.00 \\
1.00 \\
1.00 \\
1.00 \\
1.00 \\
.60 \\
.35 \\
1.15 \\
1.00 \\
.20 \\
1.00 \\
1.00 \\
1.00 \\
1.00 \\
1.00 \\
1.30 \\
1.00\end{array}$ & $\begin{array}{r}1.00 \\
.65 \\
.60 \\
.60 \\
.50 \\
.30 \\
.60 \\
1.00 \\
.50 \\
1.00 \\
1.00 \\
1.00 \\
1.00 \\
1.60 \\
1.00 \\
.30 \\
.60 \\
.50 \\
1.00 \\
.60 \\
1.00 \\
1.00 \\
1.00 \\
1.00 \\
1.00 \\
1.40 \\
1.00\end{array}$ & 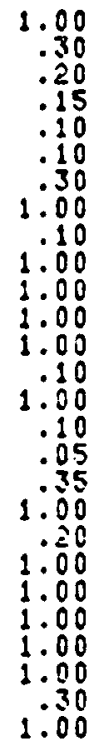 \\
\hline
\end{tabular}

TABLE VI. 1985 Technology Projection and Estimated Probability Matrix

\begin{tabular}{|c|c|c|c|c|c|c|c|}
\hline $\begin{array}{l}\text { Item } \\
\text { No. }\end{array}$ & Present & $\begin{array}{l}\text { Near- } \\
\text { Future }\end{array}$ & Future & Limit & \multicolumn{3}{|c|}{ Probability } \\
\hline $\begin{array}{r}1 \\
2 \\
3 \\
4 \\
5 \\
6 \\
7 \\
8 \\
9 \\
10 \\
11 \\
12 \\
13 \\
14 \\
15 \\
16 \\
17 \\
18 \\
19 \\
20 \\
21 \\
22 \\
23 \\
24 \\
25 \\
26 \\
27\end{array}$ & $\begin{array}{r}.00 \\
2.50 \\
30.00 \\
20.30 \\
20.00 \\
500000.00 \\
7.00 \\
70.00 \\
70.00 \\
.00 \\
.00 \\
.00 \\
.000 \\
.50 \\
65.00 \\
80.00 \\
30.00 \\
.00 \\
12.00 \\
.00 \\
.00 \\
.00 \\
.00 \\
.00 \\
0.00 \\
.00\end{array}$ & $\begin{array}{r}1.00 \\
5.00 \\
40.00 \\
80.20 \\
80.00 \\
25000.00 \\
8.00 \\
10.00 \\
80.00 \\
25000.05 \\
20000.00 \\
10000.05 \\
45.00 \\
85.00 \\
25.00 \\
11.05 \\
11.00 \\
50.00 \\
10.00 \\
10.00 \\
10.00 \\
168.00 \\
10.00 \\
1.00\end{array}$ & $\begin{array}{r}1.00 \\
10.00 \\
50.00 \\
90.15 \\
90000 \\
20000.00 \\
10.000 \\
10.00 \\
90.00 \\
25000.05 \\
20000.00 \\
1000 \\
10000.00 \\
30.00 \\
90.00 \\
20.00 \\
10.05 \\
10.00 \\
50.00 \\
10.00 \\
10.00 \\
10.00 \\
168.00 \\
12.00 \\
1.00\end{array}$ & $\begin{array}{r}1.00 \\
25.00 \\
60.00 \\
9.100 \\
95.00 \\
15000.00 \\
12.00 \\
10.00 \\
95.00 \\
25000.05 \\
20000.100 \\
.000 \\
10000.00 \\
5.00 \\
95.00 \\
10.00 \\
0.05 \\
50.00 \\
50.00 \\
10.00 \\
10.00 \\
10.00 \\
168.00 \\
15.00 \\
1.00\end{array}$ & 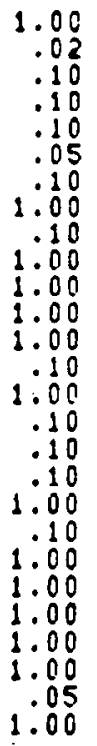 & $\begin{array}{l}1.00 \\
.28 \\
.40 \\
.60 \\
.65 \\
.70 \\
.30 \\
1.00 \\
.60 \\
1.00 \\
1.00 \\
1.00 \\
1.00 \\
.60 \\
1.00 \\
.50 \\
.60 \\
.40 \\
1.00 \\
1.30 \\
1.00 \\
1.00 \\
1.00 \\
1.00 \\
1.00 \\
1.35 \\
1.00\end{array}$ & $\begin{array}{r}1.00 \\
.70 \\
.50 \\
.30 \\
.25 \\
.25 \\
.60 \\
1.80 \\
.30 \\
1.00 \\
1.00 \\
1.00 \\
1.00 \\
.30 \\
1.00 \\
.40 \\
.30 \\
.00 \\
1.00 \\
.60 \\
1.00 \\
1.00 \\
1.00 \\
1.00 \\
1.00 \\
1.60 \\
1.00\end{array}$ \\
\hline
\end{tabular}


as the width limit and reflecting a reasonably high degree of confidence $(0.65$ probability) that, by 1980 , the width will be somewhere between 5 and $10 \mathrm{~cm}$. Our current projection for 1985 is that the probability is good (0.70) that silicon sheets between 10 and $25 \mathrm{~cm}$ wide will be pulled.

Doubling the growth rate from 30 to $60 \%$, and, at the same time, reducing thickness to $0.10 \mathrm{~mm}$, still represents a formidable, yet not impossible, challenge. This is also reflected in the estimated lower probabilities for growth rate $(1980: 0.20 .60 .2 ; 1985: 0.10 .40 .5)$. Yield (1tems 5 and 17) and equipment availability (1tem 9) are difficult to project from laboratory conditions, but, from our experience in semiconductor manufacturing, tend to requite diligent engineering effort, rather than technology breakthroughs, to improve. This is the basis for our optimistic outlook.

Future silicon-sheet pullers are envistoned as mass-proluced ( $\$ 20,000)$, special-purpose machines, highly reliable with automatic melt replenishment, and capable of near-unattended growth. If equipment meeting these conditions does not become avallable, perhaps because of Insufficient demand for solar-cell products, then the outlook for photovoltalcs should be reassessed. 
4. 4 Computer Evaluation

With the method described In section 3 , the production-unit computer model was iterated 600 times for each of the two years $(1980,1985)$. Each time, from a different set of input variables, energy-calacity cost at the level of sheet material was computed. Three of the 600 sets of input variables for 1980, which resulted in the highest $(\$ 2492 / \mathrm{kWE})$ and two lowest-cost (\$203/kWE and $\$ 96 / \mathrm{kWE})$ figures, are listed in Fis. 9. The result of calculation and of the subsequent statistical analysis can be seen in Tables VII and VIII. Similar information for 1985 is shown in Fig. 10 and $T a b l \in S$ IX ard $X$.

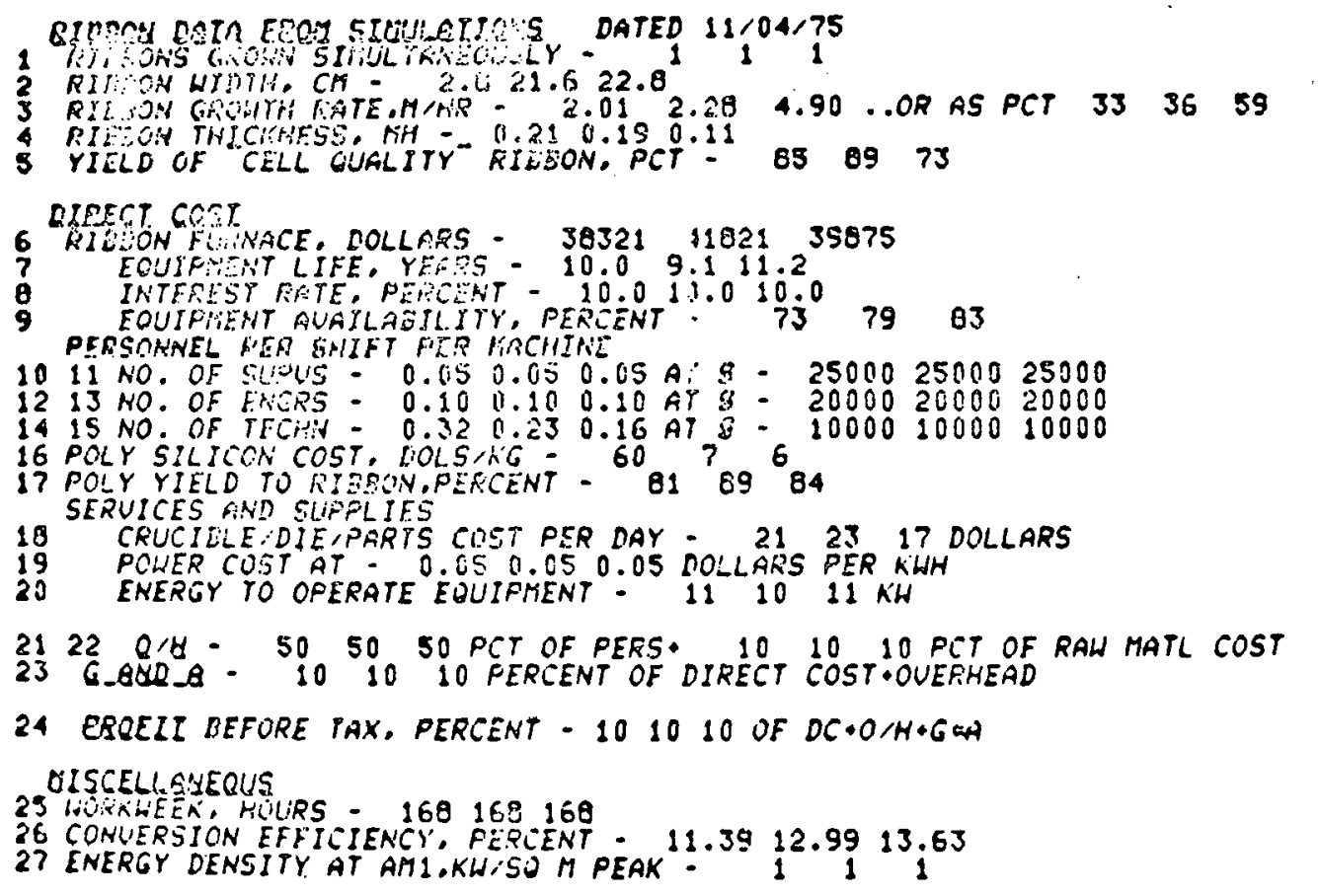

Fig. 9. 1980 list of input parameters resulting in the highest and two lowest energy-capacity costs. 
TABLE VII. Three Sample (Highest and Two Lowest) Energy-Capacity Cost Calculations for 1980

\begin{tabular}{|c|c|c|c|}
\hline RIDBons GeON SImLLTANEOUSLY & 1.00 & 1.00 & 2.00 \\
\hline RIBEOW HIDTH, CH & 2.62 & 21.64 & 22.70 \\
\hline AW ND AREA GRUTH RTE,SO M/HR & 0.03 & 0.35 & 0.67 \\
\hline CONEINED YIELD FACTOR & 0.69 & 0.79 & 0.61 \\
\hline $\begin{array}{l}\text { DIRECT COST IN DOLSISO METER } \\
\text { EOUIPHENT CAPITAL RECOUERY } \\
\text { PERSONAEL CON COST } \\
\text { POLY SILICON COST } \\
\text { SERUICES/SUPPLIES }\end{array}$ & $\begin{array}{l}21.31 \\
91.76 \\
43.19 \\
29.43\end{array}$ & $\begin{array}{l}2.47 \\
7.97 \\
3.91 \\
3.12\end{array}$ & $\begin{array}{l}1.07 \\
3: 58 \\
2.76 \\
1.39\end{array}$ \\
\hline SUBTOTAL: & 185.70 & 17.48 & 8.01 \\
\hline $\begin{array}{l}\text { QUERHEAD COST IN DOLS'SO METER } \\
\text { GATEXPENSES IN DOLS'SS METER } \\
\text { PROFIT IN DOLLARS'SO METER }\end{array}$ & $\begin{array}{l}48.85 \\
23.46 \\
25.80\end{array}$ & $\begin{array}{l}4.30 \\
2.10 \\
2.39\end{array}$ & $\begin{array}{l}1.96 \\
1.08 \\
1.10\end{array}$ \\
\hline TOTAL COST IN DOLSISO METER & 283.81 & 26.34 & 23.03 \\
\hline DOLLARS PER KH & 2491.97 & 202.79 & 95.58 \\
\hline
\end{tabular}

TABLE VIII. Statistical Analysis of 1980 Energy-Capacity Cost Figures

\begin{tabular}{lc} 
Parameter & Value \\
\cline { 2 - 2 } Sample size & 600 \\
Maximum & 2492 \\
Minimum & 96 \\
Range & 2396 \\
Mean & 769.605 \\
Variance & 105026 \\
Standard deviation & 324.078 \\
Mean deviation & 246.311 \\
Median. & 725 \\
Mode & 681 \\
\hline
\end{tabular}




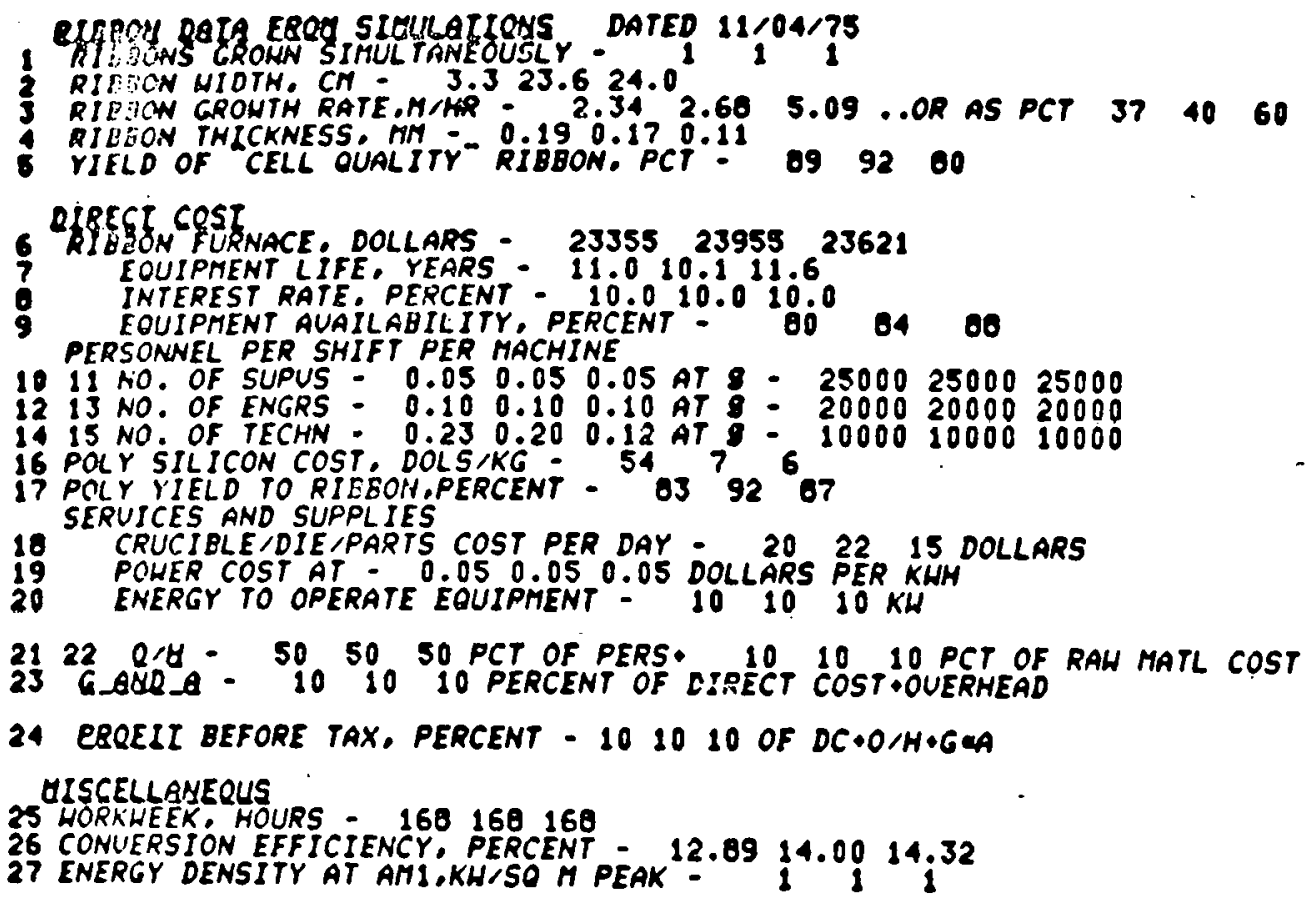

Fig. 10. 1985 list of input parameters resulting in the highest and two lowest energy-capacity costs.

TABLE IX. Three Sample (Highest and Two Lowest)

Energy-Capacity Cost Calculations for 1985

\begin{tabular}{|c|c|c|c|}
\hline RIBDONS GROAN SImLLTANEOUSLY & 1.00 & 2.00 & 1.00 \\
\hline RIDDaw HIDTH. Cn & 3.29 & 23.56 & 24.05 \\
\hline US UD AREA GRUTH RTE.SO M/AR & 0.05 & 0.49 & 0.86 \\
\hline OMSINED YIELD FACTOR & 0.73 & 0.05 & 0.69 \\
\hline $\begin{array}{l}\text { OIAECT COST IN DOLS/SO METER } \\
\text { EQUIPMENT CAPITAL RECOUERY } \\
\text { PERSONNEL } \\
\text { POL Y SILICON COST } \\
\text { SERUICESISUPPLIES }\end{array}$ & $\begin{array}{l}7.06 \\
50.01 \\
32.94 \\
10.29\end{array}$ & $\begin{array}{l}0.94 \\
5.32 \\
3.40 \\
2.14\end{array}$ & $\begin{array}{l}0.49 \\
2.62 \\
2.29 \\
1.01\end{array}$ \\
\hline SUBTOTAL: & 109.91 & 11.81 & 6.42 \\
\hline $\begin{array}{l}\text { OUERMEAD COST IN DOLSISO METER } \\
\text { GW EXPENSES IN DOLS/SO METER } \\
\text { PROFIT IN DOLLARSISO METER }\end{array}$ & $\begin{array}{l}27 \cdot .22 \\
13 \cdot 77 \\
15.15\end{array}$ & $\begin{array}{l}2.95 \\
1.40 \\
1.62\end{array}$ & $\begin{array}{l}1.47 \\
0.79 \\
0.07\end{array}$ \\
\hline OTAL COST IN DOLSISO METER & 166.65 & 17.05 & 9.5 \\
\hline XLARS PER KH & 1292.90 & 127.56 & 66.6 \\
\hline
\end{tabular}


TABLE X. Statistical Andysis of 1985

Energy-Capacity Cost Figures

Paramcter

Sample size

Maximum

Minimum

Range

Mean

Variance

Standard deviation

Mean deviation

Median

Mode $\underline{\text { Value }}$

600

1293

67

1226

413.728

29022

170.358

128.373

385

410

Accordingly, an energy-capaclty cost for 1980 of $\$ 750 / k w E$ is projected, which is between the mean ( $\$ 770 / k W E)$ and the medjan $(\$ 725 / \mathrm{kWE})$. For 1985, the projected value is $\$ 350 / \mathrm{kWE}$, derived from the mean $(\$ 414 / \mathrm{kWE})$, the median ( $\$ 385 / \mathrm{kWE})$, and subsequent iterations. To confirm the results, the procedure was lterated another 600 times, each time with a different stream of random numbers. The statistical analysis resulced, for 1980 , in a mean of $\$ 778 / \mathrm{kWE}$ and a median of $\$ 727 / \mathrm{kWE}$. For 1985 , the values were $\$ 369 / \mathrm{kWE}$ and $\$ 342 / \mathrm{kWE}$, respectively, or about. $10 \%$ lower than the first set.

Figure 11 shows the frequency distributions of these four sets of 600 energy-capacity costs. It is noted that the 
1985 distributions are grouped considerably tighter around the median, perhaps because our probability estimates have less variation for that later point in time.
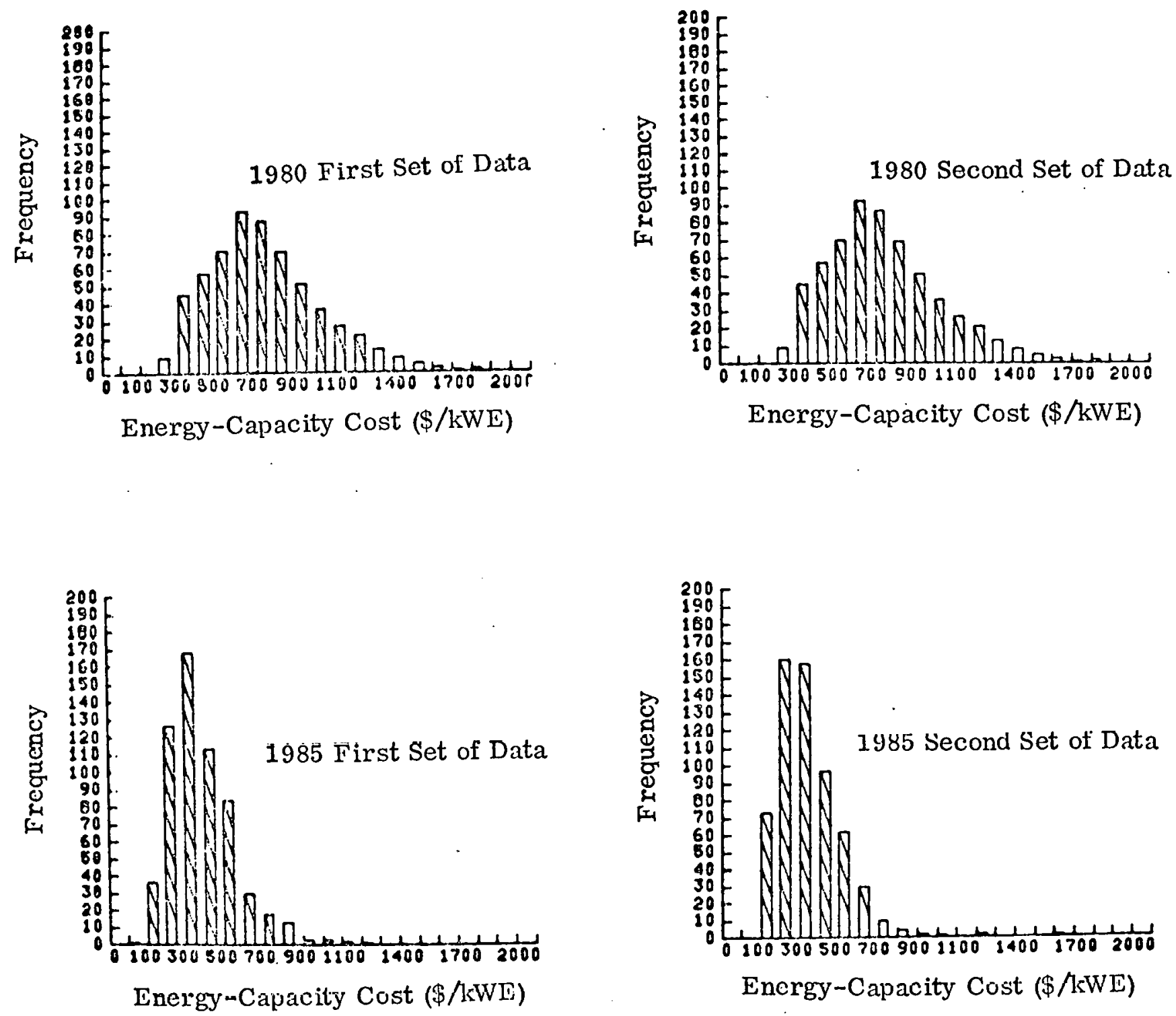

Fig. 11. Frequency distribution of calculated energy-capacity costs. 
At JPL's suggestion, a further statistical test was performed, again using a different random number seed, primarily to confirm that a steady state had been reached. The result of the 1985 calculation, shown in Table XI, confirmed this condition. As shown, 2223 calculations were performed (first column) before the APL workspace was full, and calculation was terminated. Intermediate results were printed every 60 lines. The second column shows the mean, the third the median, and the last three the standard deviation, the mean deviation, and the remaining workspace size.

TABILE XI. Statistical Analysis of 1985 Energy-Capacity Cost Figures, Including Iterations

\begin{tabular}{|c|c|c|c|c|c|}
\hline $\begin{array}{l}\text { Iier- } \\
\text { ation }\end{array}$ & Mean & Medjan & $\begin{array}{l}\text { Standard } \\
\text { Deviation }\end{array}$ & $\begin{array}{l}\text { Mean } \\
\text { Deviation }\end{array}$ & AWA \\
\hline $\begin{array}{l}63 \\
63 \\
123 \\
103 \\
2143 \\
303 \\
363 \\
423 \\
483 \\
543 \\
603 \\
663 \\
123 \\
783 \\
843 \\
903 \\
963 \\
1023 \\
1083 \\
1143 \\
1203 \\
1263 \\
1323 \\
1383 \\
1443 \\
1503 \\
1563 \\
1623 \\
1683 \\
1743 \\
1803 \\
1863 \\
1923 \\
1983 \\
2043 \\
2103 \\
2163 \\
2223\end{array}$ & $\begin{array}{l}204 \\
369 \\
363 \\
359 \\
353 \\
355 \\
353 \\
351 \\
355 \\
360 \\
359 \\
362 \\
361 \\
361 \\
362 \\
361 \\
362 \\
363 \\
362 \\
363 \\
362 \\
363 \\
364 \\
362 \\
363 \\
363 \\
363 \\
363 \\
364 \\
363 \\
364 \\
365 \\
365 \\
365 \\
365 \\
365 \\
365 \\
365\end{array}$ & $\begin{array}{l}269 \\
343 \\
347 \\
347 \\
335 \\
332 \\
331 \\
330 \\
334 \\
337 \\
338 \\
342 \\
340 \\
339 \\
340 \\
338 \\
340 \\
339 \\
336 \\
336 \\
336 \\
336 \\
338 \\
335 \\
335 \\
336 \\
336 \\
337 \\
339 \\
338 \\
338 \\
339 \\
339 \\
340 \\
341 \\
341 \\
340 \\
340\end{array}$ & $\begin{array}{l}122 \\
146 \\
130 \\
128 \\
130 \\
143 \\
138 \\
141 \\
147 \\
153 \\
152 \\
155 \\
155 \\
153 \\
152 \\
155 \\
154 \\
156 \\
156 \\
159 \\
158 \\
160 \\
160 \\
159 \\
159 \\
158 \\
157 \\
157 \\
157 \\
156 \\
156 \\
156 \\
157 \\
156 \\
156 \\
155 \\
156 \\
157\end{array}$ & $\begin{array}{l}06 \\
119 \\
102 \\
101 \\
103 \\
100 \\
105 \\
107 \\
111 \\
114 \\
114 \\
117 \\
117 \\
116 \\
116 \\
117 \\
117 \\
118 \\
118 \\
120 \\
120 \\
121 \\
121 \\
121 \\
120 \\
119 \\
119 \\
119 \\
119 \\
118 \\
118 \\
119 \\
119 \\
118 \\
118 \\
118 \\
118 \\
110\end{array}$ & $\begin{array}{l}45204 \\
44724 \\
44244 \\
43764 \\
43284 \\
42804 \\
42324 \\
41844 \\
41354 \\
40804 \\
40404 \\
39924 \\
39444 \\
38964 \\
38484 \\
38004 \\
37524 \\
37044 \\
36564 \\
36084 \\
35604 \\
35124 \\
34644 \\
34164 \\
33684 \\
33204 \\
32724 \\
32244 \\
31764 \\
31284 \\
30804 \\
30324 \\
20844 \\
29364 \\
28684 \\
280404 \\
27924 \\
27444\end{array}$ \\
\hline
\end{tabular}


4.5 Analysis of Results

An Important consideration is whether or not this "bottoms-up" process-related analysis supports the projections of future energy-capacity cost arrived at by other means. To analyze this further, ERDA-projected (4) "established silicon array costs" are plotted together with the results of this study in Fig. 12, where both a regular plot and a $10 \mathrm{~g}$ plot are shown.
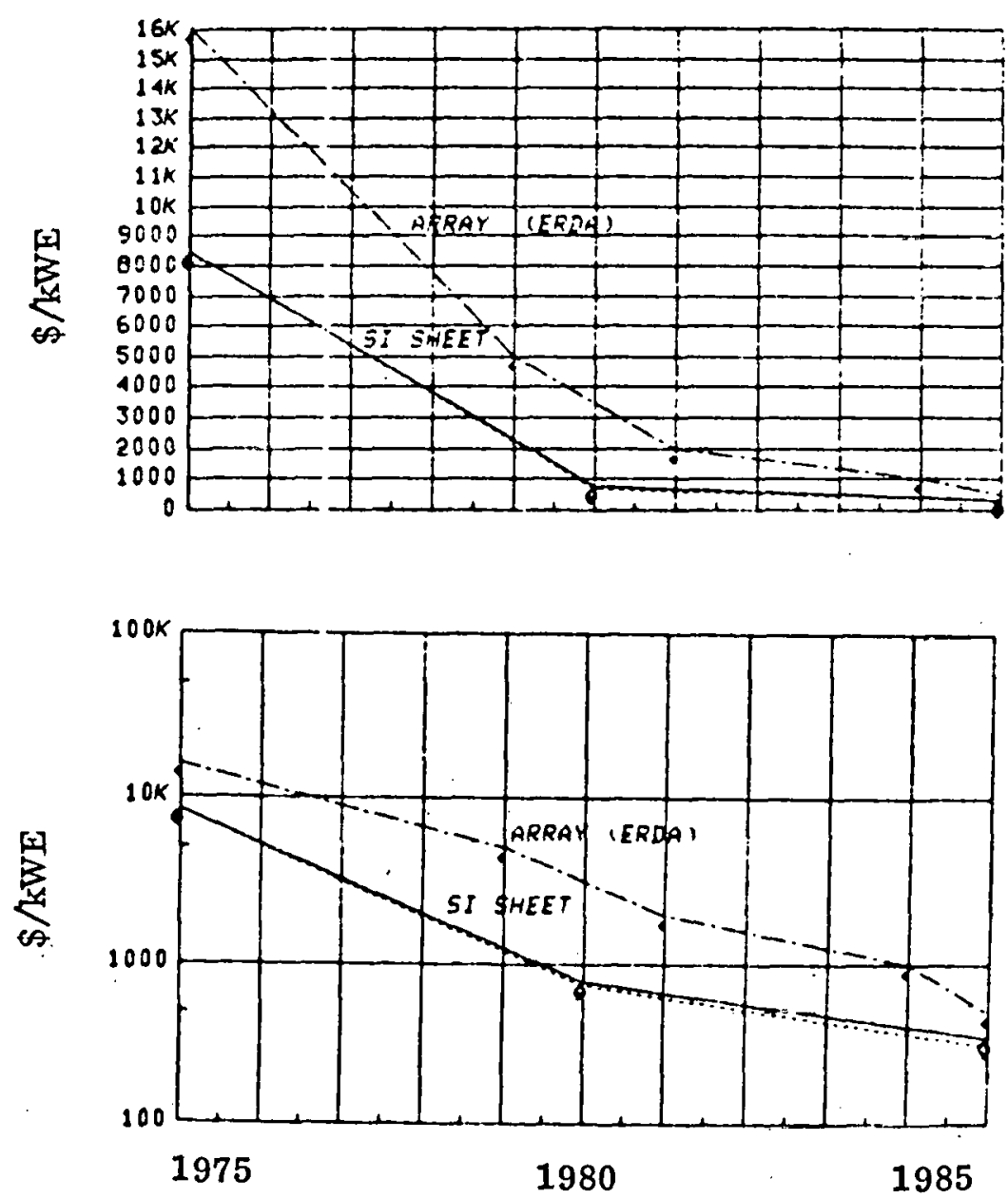

Fig. 12. Plot and log plot of projected silicon-sheet material and array cost versus time. 
Generally speaking, the value of single-crystal silicon material should not exceed $30 \%$ of array cost. For the remainder of this decade, as can be seen from Fig. 12, our projection of energy-capacity cost at the silicon-sheet material level is somewhat less than half of the array cost projected by ERDA and thus within the accuracy level of this type of projection. From 1980 through 1985, however, this band narrows to a point in 1985 where profected energy-capacity cost at the level of sheet material ( $\$ 350 / \mathrm{kWE})$ almost equals array cost $(\$ 500 / \mathrm{kWE})$.

In sum, it is concluded that compatibility and general agreement exist between this study and ERDA projections, particularly through 1980 .

\section{CONCLUSIONS}

A new technology forecasting technique is being developed ana applied to projecting the future cost of energy at the level of silicon-sheet material. This technique is based upon the production-unit concept and deals with the economics of material manufacturing from a processing parameter, or "bottoms up," standpoint. From a baseline, or state-of-the-art, future technology capability is profected through full maturity. 
The concept of chronology is introduced by estimating the probability of meeting the obfective associated with the technology parameter at a stated point in time. From this probability density function, the cumulative probability distribution function is derived. The latter function is evaluated numerically, thus providing a set of input parameters to the production-unit model. Calculation, followed by subsequent iteration of this procedure, and final statistical analysis of the accumulated output from the model form the basis for the profected energy-capacity cost versus time relationship.

Application of. this technique results in the following outlook for large-area si11con sheets:

- Silicon-sheet technology has the potential for achleving future low-cost material objectlves for photovoltaic applications, if devilopment milestones defined in this study are met.

- 1980 and 1985 energy-capac1ty costs of $\$ 750 / \mathrm{kWE}$ and $\$ 350 / \mathrm{kWE}$, respectively, at the level of s111con-sheet material, are projected.

- This analysis confirms, from a silicon-sheet material standpoint, that ERDA=stated 
energy-capacity cost objectives at the array level are achlevable. However, there appears to be little, if any, margin for error.

- Through 1980, a factor of 22 difference exists between ERDA-projected costs at the array level and our cost at the sllicon-sheet material level. By 1985, this difference has essentially disappeared $(\$ 500 / \mathrm{kWE}$ and $\$ 350 / \mathrm{kWE})$, which is an undesirable cost trend requiring further analysis.

6. REFERENCES

1. Quarterly Technical Progress Report Number 2, JPL Contract 954144 , G. H. Schwuttke, Principal Investigator, December: 15,1975 .

2. Geoffrey Gordon, System Simulation, Prent1ce-Hall, Inc., New Jersey (196\%).

3. Quarterly Technical Progress Report Number 3, JPL Contract 954144 , G. H. Schwuttke, Principal Investigator, March $15,1976$.

4. Proceedings of the First ERDA semiannual solar Photovoltaic Conversjon Program Conference, p. 11 , UCLA, July 22-25, 1975 . 
FIFTH QUARTER ACTIVITY PLAN

- Continue process studies on ribbon perfection.

o Optimize 38-mm-wide ribbon growth.

- Study influence of ribbon defects on lifetime and solar-cell efficiency.

- Continue work on comparative analysis of materialarea throughput capability between capillary action shaping technique and Czochralski processing, using computer graphics.

- Expand ribbon-growth computer model to address other materia1-processing steps. 